\title{
Estimation of phase separation temperatures for polyethersulfone/solvent/non-solvent systems in RTIPS and membrane properties
}

\author{
Liu, Min; Liu, Sheng-Hui; Skov, Anne Ladegaard; Xu, Zhen-Liang
}

Published in:

Journal of Membrane Science

Link to article, DOI:

10.1016/j.memsci.2018.04.006

Publication date:

2018

Document Version

Peer reviewed version

Link back to DTU Orbit

Citation (APA):

Liu, M., Liu, S-H., Skov, A. L., \& Xu, Z-L. (2018). Estimation of phase separation temperatures for polyethersulfone/solvent/non-solvent systems in RTIPS and membrane properties. Journal of Membrane Science, 556, 329-341. https://doi.org/10.1016/j.memsci.2018.04.006

\section{General rights}

Copyright and moral rights for the publications made accessible in the public portal are retained by the authors and/or other copyright owners and it is a condition of accessing publications that users recognise and abide by the legal requirements associated with these rights.

- Users may download and print one copy of any publication from the public portal for the purpose of private study or research.

- You may not further distribute the material or use it for any profit-making activity or commercial gain

- You may freely distribute the URL identifying the publication in the public portal 


\section{Author's Accepted Manuscript}

Estimation of phase separation temperatures for polyethersulfone/solvent/non-solvent systems in RTIPS and membrane properties

Min Liu, Sheng-Hui Liu, Anne Ladegaard Skov, Zhen-Liang Xu

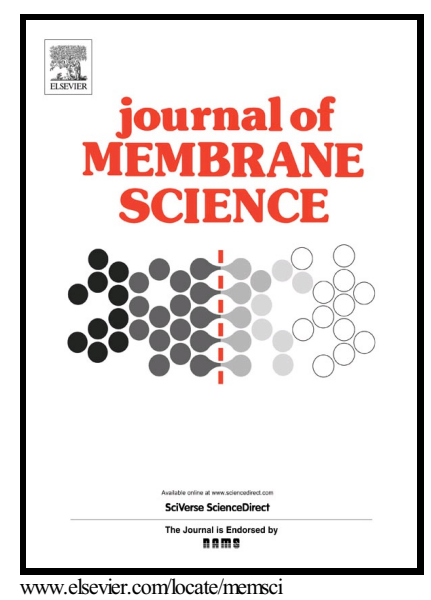

PII: $\quad$ S0376-7388(18)30276-X

DOI: $\quad$ https://doi.org/10.1016/j.memsci.2018.04.006

Reference: MEMSCI16090

To appear in: Journal of Membrane Science

Received date: 30 January 2018

Revised date: 5 April 2018

Accepted date: 7 April 2018

Cite this article as: Min Liu, Sheng-Hui Liu, Anne Ladegaard Skov and ZhenLiang $\mathrm{Xu}$, Estimation of phase separation temperatures for polyethersulfone/solvent/non-solvent systems in RTIPS and membrane p r o p e r t i e s, Journal of Membrane Science, https://doi.org/10.1016/j.memsci.2018.04.006

This is a PDF file of an unedited manuscript that has been accepted for publication. As a service to our customers we are providing this early version of the manuscript. The manuscript will undergo copyediting, typesetting, and review of the resulting galley proof before it is published in its final citable form. Please note that during the production process errors may be discovered which could affect the content, and all legal disclaimers that apply to the journal pertain. 


\title{
Estimation of phase separation temperatures for
}

\section{polyethersulfone/solvent/non-solvent systems in RTIPS and membrane properties}

\author{
Min Liu ${ }^{\text {a, c }}$, Sheng-Hui Liu ${ }^{\text {b }}$, Anne Ladegaard Skov ${ }^{c}$, Zhen-Liang Xu ${ }^{\text {a, b,* }}$ \\ ${ }^{a}$ Key Laboratory for Ultrafine Materials of Ministry of Education, Shanghai Key Laboratory of \\ Advanced Polymeric Materials, School of Materials Science and Engineering, East China University \\ of Science and Technology (ECUST), 130 Meilong Road, Shanghai 200237, China \\ b State Key Laboratory of Chemical Engineering, Membrane Science and Engineering R\&D Lab, \\ Chemical Engineering Research Center, ECUST, 130 Meilong Road, Shanghai 200237, China \\ ${ }^{c}$ Danish Polymer Center, Department of Chemical and Biochemical Engineering, Technical \\ University of Denmark, Building 227, 2800 Kgs. Lyngby, Denmark \\ * To whom all correspondence should be addressed. Email: chemxuzl@ecust.edu.cn; Tel: 86-21- 64253061; Fax:
} 86-21-64252989.

\section{ABSTRACT:}

Phase separation temperature estimations, based on Hansen solubility parameters for poly(ethersulfone) (PES)/solvent/non-solvent systems, were carried out to study the control of phase separation temperature in a reverse thermally induced phase separation (RTIPS) process. Four membrane-forming systems were studied, namely PES/N,N-dimethylacetamide (DMAc)/diethylene glycol (DEG), PES/DMAc/polyethylene glycol 200 (PEG200), PES/DMAc/PEG300 and PES/DMAc/PEG400. The effects of PES molecular weights, PES concentrations, PEG molecular weights and ratios of non-solvent/solvent on phase separation temperature are investigated, and the theoretical Hansen solubility parameter calculation is used to establish a prediction equation for phase separation temperature. A linear relationship between the experimental data and the difference in the 


\section{ACCEPTED MANUSCRIPT}

solubility parameters between PES and the mixed solvent was observed. When the membrane-forming temperature was higher than the cloud point, membranes with a bi-continuous structure were acquired and showed a higher pure water permeation flux than that of membranes prepared with the non-solvent induced phase separation (NIPS) process. The pure water permeation flux and the mean pore size of membranes prepared with the RTIPS process decreased in line with an increase of PES molecular weight. When the membrane formation mechanism was the RTIPS process, the mechanical properties were better than those of the corresponding membranes prepared with the NIPS process.

\section{Keywords:}

polyethersulfone, membrane, phase separation temperature, reverse thermally induced phase separation

\section{Introduction}

Polyethersulfone (PES) consisting of rigid phenyl and flexible ether groups, aligned with a conjugated structural unit, chemical resistance, good molecular stability and excellent mechanical properties, and has been widely used for membrane materials [1-3].

Many studies have been successfully prepared PES membranes by employing non-solvent induced phase separation (NIPS) [4-6]. In the NIPS process, the phase separation driving force involves mass transfer between the solvent in the casting solution and the non-solvent in a coagulation bath. As a result of the fast mass transfer, the morphology of PES membranes formed by the NIPS method often shows a dense skin layer and finger-like pores, which usually result in a low permeation flux and poor mechanical properties $[7,8]$. Modifications to the NIPS process for better PES membranes have been 


\section{ACCEPTED MANUSCRIPT}

investigated extensively [9-13].

Commonly employed approaches include the addition of additives to the casting solutions or coagulations $[14,15]$, the introduction of an extra process $[16,17]$ and chemical modification $[18,19]$. Nevertheless, these modification methods result in complicated membrane-forming processes, which subsequently lead to an increase in production costs.

As a new membrane formation technology, Castro first introduced the thermally induced phase separation (TIPS) method in 1981 [20]. In the TIPS process, an upper critical solution temperature (UCST) system is used to prepare polymer membranes. The phase separation driving force is heat transfer. Compared to the NIPS method, there are fewer variables to control [21-26], and the prepared membranes have a porous skin layer and bi-continuous pores, which usually results in a high permeation flux and good mechanical properties. Crystalline polymers, such as polypropylene (PP) [28], polyethylene (PE) [29], poly(vinylidene fluroride) (PVDF) [30], poly(ethylene-co-vinyl alcohol) (EVOH) [31], ethylene-acrylic acid copolymer (EAA) [32], polyphenylene (PPS) [33], poly(ether ether ketone) (PEEK) [34], poly(oxymethylene) (POM) [35], poly(ethylene chlorotrifluoroethylene) (PECTFE) [36], poly(4-methyl-1pentene) (PMP) [37] and poly(L-lactic acid) (PLLA) [38], as well as amorphous polymers, such as poly(vinyl butyral) (PVB) [39], poly(methyl methacrylate) (PMMA) [40] and polystyrene (PS) [41], have been prepared successfully by using the TIPS process. Moreover, some researchers have focused on simulating the phase separation dynamics of membrane formation in TIPS $[42,43]$. Despite its versatility and success, a lack of suitable diluents is one of the main reasons for the TIPS process being challenging for the large scale industrial production of many polymer membrane materials. Moreover, the high processing temperature also limits the wide use of the TIPS method. 


\section{ACCEPTED MANUSCRIPT}

Thus, several new improvements to the TIPS method have been reported [44-48]. Matsuyama et al. [44], for instance, first reported a new technology combining TIPS and NIPS to prepare PMMA microporous membranes. Methanol was used as non-solvent, resulting in the TIPS process and NIPS process occurring simultaneously. As result, a membrane with small pores, which were formed by TIPS near the bottom surface, was prepared. Li et al. [45] achieved the transition of the membrane structure from a typical finger-like morphology to a leaf-like network structure by mixing the solvent N,N-dimethylacetamide (DMAc) and the diluent dibutyl phthalate (DBP), while Cha et al. [46] realised a change in $\alpha$-type crystallite PVDF to $\beta$-type crystallite PVDF by introducing a solvent (DMAc) into the coagulation bath. This method was named "modified TIPS" (m-TIPS). Water flux and the mean pore size of the prepared PVDF membrane increased, but mechanical strength decreased. Complex TIPS (c-TIPS) was proposed by Zhu et al. [47], the highlight of which lies in a complex diluent that is mixture of a water-soluble good solvent and a water-soluble additive. PVDF and polystyrene (PS) membranes with high strength and water flux can be obtained. Low TIPS (L-TIPS) was presented by Lu et al. [48], whereby a self-synthesised additive was utilised and the spinning dope temperature of L-TIPS was lower than that of traditional TIPS. A PVDF membrane with sponge-like pores in the middle was obtained, but a few finger-like pores still co-existed.

Our earlier studies [49-52] have posited a reverse thermally induced phase separation (RTIPS) technology. The employed casting solution features a low critical solution temperature (LCST) and the driving force for phase separation is induced by heat transfer, albeit in an opposite manner of TIPS. The RTIPS technology combines a low membrane-forming temperature with fast heat transfer. PES [49] and polysulfone (PSF) [52] membranes can be successfully attained via RTIPS, and the prepared membranes with porous skin have shown high water flux and good mechanical properties. The key 


\section{ACCEPTED MANUSCRIPT}

factor affecting PES membrane formation mechanism is the phase separation temperature of the LCST casting solutions. However, there are no previous studies about the theoretical estimation of the phase separation temperature of PES membrane-forming systems via RTIPS. In this study, therefore, the phase separation temperature of PES/solvent/non-solvent ternary systems with LCST was examined, and the theoretical prediction was achieved through Hansen solubility parameters. DMAc was used as a solvent, and diethylene glycol (DEG) and polyethylene glycol (PEG) with molecular weights of 200, 300 and 400 were used as non-solvents. Moreover, the effects of PES concentration, PEG molecular weight, and membrane-forming temperature on the PES membrane structure and performances are discussed in detail.

\section{Experimental}

\subsection{Materials}

Three different polyethersulfones (PES) were used as membrane material in this study. The average molecular weights (stated in units of g/mol) were 51,000 (E6020P, BASF Co. Ltd., German), 62,000 (VERADEL 3000P, Solvay Specialty Polymers USA, LLC) and 77,000 (Jilin Jida High Performance Materials Co. Ltd., China). The polymers are abbreviated herein as PES51000, PES62000 and PES77000, respectively. All three polymers were dried at $60^{\circ} \mathrm{C}$ before use. N,N-dimethylacetamide (DMAc), diethylene glycol (DEG), polyethylene glycols with molecular weights of 200, 300 and 400, respectively (PEG200, PEG300 and PEG400), and ethanol were purchased from Shanghai Chemical Reagent Co. Ltd. Bovine serum albumin (BSA, average molecular weight of 67,000) was obtained from Shanghai Lianguan Biochemical Engineering Co., Ltd.). All chemicals were used without further purification.

\subsection{Preparation of the casting solutions}

The compositions of the PES/solvent/non-solvent casting solutions are shown in Table 1 and Table

2. DMAc is a solvent for PES, and DEG and the three types PEG are non-solvents for PES. 


\section{ACCEPTED MANUSCRIPT}

Homogeneous casting solutions were obtained by stirring for $48 \mathrm{~h}$ at $25^{\circ} \mathrm{C}$, following which the solutions were degassed under atmospheric pressure for one day at room temperature.

Table 1 Compositions of the PES/DMAc/DEG casting solutions.

\begin{tabular}{cccccc}
\hline \multirow{2}{*}{ Casting solutions } & Types of PES & \multicolumn{2}{l}{ Casting solution compositions (wt.\%) } & $\begin{array}{c}\text { Mass ratio of } \\
\text { DEG/DMAc } \\
\text { (wt. /wt.) }\end{array}$ \\
\cline { 3 - 5 } & PES & DMAc & DEG & $1.0: 1.0$ \\
MDEG1-10 & 10.0 & 41.5 & 41.5 & $1.0: 1.0$ \\
MDEG1-12 & 12.0 & 41.5 & 41.5 & $1.0: 1.0$ \\
MDEG1-14 & & 14.0 & 41.5 & 41.5 & $1.0: 1.0$ \\
MDEG1-15.5 & & 15.5 & 41.5 & 41.5 & $1.0: 1.0$ \\
MDEG1-17a & PES51000 & 17.0 & 41.5 & 41.5 & $0.95: 1.0$ \\
MDEG1-17b & & 17.0 & 42.6 & 40.4 & $0.9: 1.0$ \\
MDEG1-17c & & 17.0 & 43.7 & 39.3 & $0.8: 1.0$ \\
MDEG1-17d & & 17.0 & 46.1 & 36.9 & $0.75: 1.0$ \\
MDEG1-17e & & 17.0 & 47.4 & 35.6 & $0.7: 1.0$ \\
MDEG1-17f & & 17.0 & 48.8 & 34.2 & $1.0: 1.0$ \\
\hline MDEG2-17 & PES62000 & 17.0 & 41.5 & 41.5 & $1.0: 1.0$ \\
\hline MDEG3-17 & PES77000 & 17.0 & 41.5 & 41.5 & \\
\hline
\end{tabular}

Table 2 Compositions of the PES/DMAc/PEG casting solutions.

\begin{tabular}{|c|c|c|c|c|c|}
\hline \multirow{2}{*}{ Casting solutions } & \multirow{2}{*}{ Types of PES } & \multicolumn{3}{|c|}{ Casting solution compositions (wt.\%) } & \multirow{2}{*}{$\begin{array}{c}\text { Mass ratio of } \\
\text { PEG/DMAc } \\
\text { (wt. /wt.) }\end{array}$} \\
\hline & & PES & DMAc & PEG & \\
\hline MPEG200-1 & \multirow{6}{*}{ PES51000 } & 17.0 & 34.6 & 48.4 & $1.4: 1$ \\
\hline MPEG200-2 & & 17.0 & 38.5 & 82.6 & $1.6: 1$ \\
\hline MPEG200-3 & & 17.0 & 27.7 & 55.3 & 2.0:1 \\
\hline MPEG200-4 & & 17.0 & 25.1 & 57.9 & 2.3:1 \\
\hline MPEG200-5 & & 17.0 & 20.75 & 62.25 & $3.0: 1$ \\
\hline MPEG200-6 & & 17.0 & 15.1 & 67.9 & $4.5: 1$ \\
\hline MPEG300-1 & \multirow{6}{*}{ PES51000 } & 17.0 & 20.75 & 62.25 & $3.0: 1$ \\
\hline MPEG300-2 & & 17.0 & 16.6 & 66.4 & $4.0: 1$ \\
\hline MPEG300-3 & & 17.0 & 13.8 & 69.2 & $5.0: 1$ \\
\hline MPEG300-4 & & 17.0 & 11.9 & 71.1 & $6.0: 1$ \\
\hline MPEG300-5 & & 17.0 & 10.4 & 72.6 & $7.0: 1$ \\
\hline MPEG300-6 & & 17.0 & 9.2 & 73.8 & $8.0: 1$ \\
\hline MPEG400-1 & \multirow{4}{*}{ PES51000 } & 17.0 & 25.1 & 57.9 & $2.3: 1$ \\
\hline MPEG400-2 & & 17.0 & 20.75 & 62.25 & $3.0: 1$ \\
\hline MPEG400-3 & & 17.0 & 15.1 & 67.9 & $4.5: 1$ \\
\hline MPEG400-4 & & 17.0 & 10.0 & 73.0 & 7.3:1 \\
\hline
\end{tabular}



MPEG400-5
17.0
9.2
73.8
$8.0: 1$

\subsection{Characterisation of the casting solutions}

\subsubsection{Cloud point determination}

The cloud point $\left(\mathrm{T}_{\mathrm{c}}\right.$ ), i.e. the lower critical solution temperature (LCST), is referred to as the "phase separation temperature" of the casting solutions. Transparent homogeneous casting solution was poured into a test tube and heated slowly in a water or oil bath, as shown in Fig. 1. As the temperature increased, phase separation occurred at a certain temperature. The onset of turbidity was considered as an indication of phase separation.

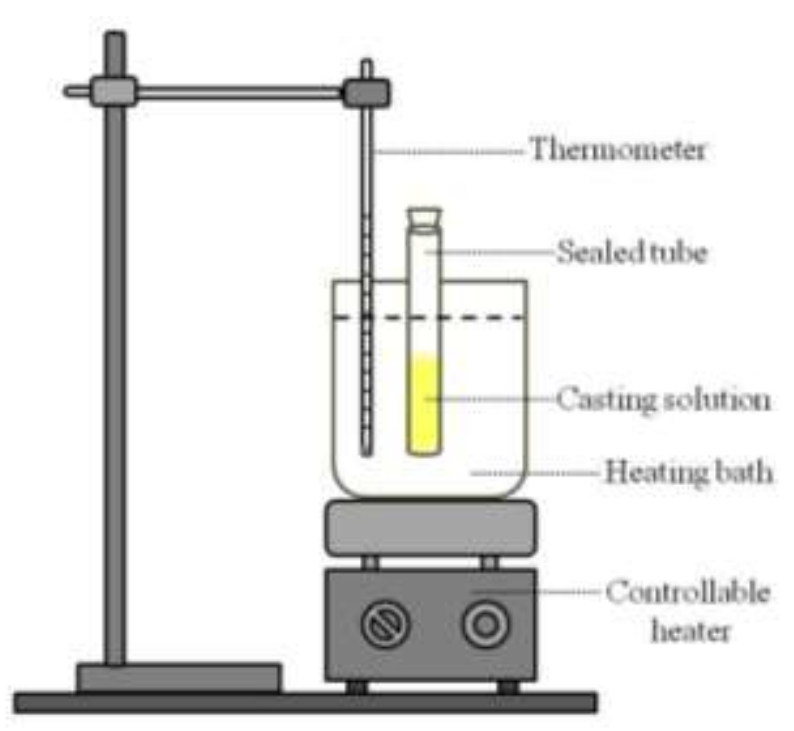

Fig. 1. Schematics of the test of cloud point

\subsubsection{Viscosity}

The viscosities of the casting solutions in various compositions were measured with a DV- IIPRO Digital Viscometer (Brookfield, USA) at $25^{\circ} \mathrm{C}$. The recorded data are the curve of viscosity to the shear rate. The reported data were the average value.

\subsubsection{Light transmittance measurement}

To investigate what is the major driving force during membrane-forming process, light transmittance experiments were carried out. The method was reported by $\mathrm{Li}$ et al [9]. The light 


\section{ACCEPTED MANUSCRIPT}

transmittance indicates the phase separation rate of the casting solution, and the intensity of the light transmittance through the membrane was recorded as a function of immersion time.

\subsection{Hansen solubility parameters}

The Hansen solubility parameter $\left(\delta_{\mathrm{t}}\right.$, total cohesion solubility parameter) [53] is composed of three parameters $\left(\delta_{\mathrm{d}}, \delta_{\mathrm{p}}\right.$ and $\left.\delta_{\mathrm{h}}\right)$ to account for nonpolar interactions $\left({ }_{\mathrm{d}}\right)$, dipolar interactions $\left(_{\mathrm{p}}\right)$ and hydrogen bonding interactions $\left({ }_{\mathrm{h}}\right)$, respectively. The Hansen solubility parameter is defined by:

$\delta_{t}^{2}=\delta_{d}^{2}+\delta_{p}^{2}+\delta_{h}^{2}$

The solubility parameter of mixed solvents is defined as:

$\delta_{i, s}=\frac{X_{1} V_{1} \delta_{i, 1}+X_{2} V_{2} \delta_{i, 2}}{X_{1} V_{1}+X_{2} V_{2}}$

where $\mathrm{X}$ is the molar fraction, $\mathrm{V}$ is the molar volume, $\delta_{\mathrm{i}, 1}(\mathrm{i}=\mathrm{d}, \mathrm{p}, \mathrm{h})$ is the $\delta_{\mathrm{t}}$ of the solvent and $\delta_{\mathrm{i}, 2}(\mathrm{i}=\mathrm{d}$, $\mathrm{p}, \mathrm{h})$ is the $\delta_{\mathrm{t}}$ of the non-solvent.

The difference in the solubility parameters between the mixed solvent and PES can then be described by [49]:

$\Delta \delta_{s-p}=\left[\left(\delta_{d, s}-\delta_{d, p}\right)^{2}+\left(\delta_{p, s}-\delta_{p, p}\right)^{2}+\left(\delta_{h, s}-\delta_{h, p}\right)^{2}\right]^{1 / 2}$

where $\delta_{\mathrm{i}, \mathrm{s}}(\mathrm{i}=\mathrm{d}, \mathrm{p}, \mathrm{h})$ are the Hansen solubility parameters of the mixed solvent and $\delta_{\mathrm{i}, \mathrm{p}}(\mathrm{i}=\mathrm{d}, \mathrm{p}, \mathrm{h})$ are the Hansen solubility parameters of PES. The values of the PES, solvent and non-slovent are listed in

Table 3. 
Table 3 Hansen solubility parameters for PES, solvent and non-solvent.

\begin{tabular}{cccccc}
\hline Components & $\begin{array}{c}\delta_{\mathrm{d}} \\
\left(\mathrm{MPa}^{1 / 2}\right)\end{array}$ & $\begin{array}{c}\delta_{\mathrm{p}} \\
\left(\mathrm{MPa}^{1 / 2}\right)\end{array}$ & $\begin{array}{c}\delta_{\mathrm{h}} \\
\left(\mathrm{MPa}^{1 / 2}\right)\end{array}$ & $\begin{array}{c}\delta_{\mathrm{t}} \\
\left(\mathrm{MPa}^{1 / 2}\right)\end{array}$ & $\begin{array}{c}\Delta \delta_{\mathrm{s}-\mathrm{p}} \\
\left(\mathrm{MPa}^{1 / 2}\right)\end{array}$ \\
\hline PES & 17.60 & 10.40 & 7.80 & 21.90 & - \\
DMAc & 16.80 & 11.50 & 10.20 & 22.70 & 2.76 \\
DEG & 16.60 & 12.00 & 20.70 & 29.12 & 13.04 \\
PEG200* & 17.97 & 6.06 & 17.30 & 25.67 & 10.45 \\
PEG300* & 17.91 & 4.73 & 15.09 & 23.89 & 9.24 \\
PEG400* & 17.88 & 4.00 & 13.85 & 22.96 & 8.81 \\
\hline
\end{tabular}

*Solubility parameters of PEG200, PEG300 and PEG400 were calculated by the group contribution method [54].

\subsection{Preparation of the PES membranes}

Flat sheet membranes were prepared by employing the RTIPS method. During the membrane formation process, deionised water was used as a coagulation bath, the temperature of which is shown in Table 4, and adjusted to the cloud point. The casting solution was cast onto a clean glass plate, using a casting knife with a gap of $300 \mu \mathrm{m}$, and then immersed into a pure water bath quickly, in order to form a membrane. The residual mixed solvent in the prepared membranes was extracted with ethanol for 2 days. The ethanol was renewed every $12 \mathrm{~h}$. These wet membranes were then dried for 2 days at room temperature, to produce dry membranes for testing. 
Table 4 Temperature of the membrane formation.

\begin{tabular}{ccc}
\hline Membrane number & Types of PES & $\begin{array}{c}\text { Water bath temperature } \\
\left({ }^{\circ} \mathrm{C}\right)\end{array}$ \\
\hline MDEG1-10-20 & PES51000 & 20 \\
MDEG1-10-50 & PES51000 & 50 \\
MDEG1-12-20 & PES51000 & 20 \\
MDEG1-12-50 & PES51000 & 50 \\
MDEG1-14-50 & PES51000 & 50 \\
MDEG1-15.5-50 & PES51000 & 50 \\
MDEG1-17a-50 & PES51000 & 50 \\
MDEG2-17-50 & PES62000 & 50 \\
MDEG3-17-50 & PES77000 & 50 \\
MPEG200-4-20 & PES51000 & 20 \\
MPEG200-4-80 & PES51000 & 80 \\
MPEG300-4-50 & PES51000 & 50 \\
MPEG300-4-80 & PES51000 & 80 \\
\hline
\end{tabular}

\subsection{Characterisation of the PES membranes}

\subsubsection{Morphology}

The morphologies of the membranes were investigated by scanning electron microscopy (SEM; S-3400 II, Hitachi High-Technologies, Japan). The cross-sections of the prepared membranes were fractured in liquid nitrogen and sputtered with gold in a vacuum.

\subsubsection{Permeation performance}

Pure water and BSA aqueous solution $\left(300 \mathrm{mg} \cdot \mathrm{L}^{-1}\right)$ were used as the feed solutions. The testing system was a dead-end stirred cell, which has been reported by Li et al. [9]. All tests were carried out at room temperature with a feed pressure of $0.1 \mathrm{MPa}$. Before the pure water permeation flux $\left(\mathrm{J}_{\mathrm{w}}\right)$ and the rejection rate $(\mathrm{R})$ of $\mathrm{BSA}$ aqueous solution were measured, the modules were pre-pressured at $0.1 \mathrm{MPa}$ with pure water for $0.5 \mathrm{~h}$. The BSA contents of the feed and the permeate solutions were 


\section{ACCEPTED MANUSCRIPT}

determined by an UV spectrophotometer (UV-300, Shimadzu, Japan), and then the $\mathrm{J}_{\mathrm{w}}$ and $\mathrm{R}$ for each membrane sample were determined three times and averaged. The $\mathrm{J}_{\mathrm{w}}$ and the $\mathrm{R}$ are defined as follows [49]:

$J_{w}=\frac{V}{A \times T}$

$R=\left(1-\frac{C_{P}}{C_{F}}\right) \times 100 \%$

where $J_{w}$ is the pure water permeation flux $\left(\mathrm{L} \cdot \mathrm{m}^{-2} \cdot \mathrm{h}^{-1}\right), \mathrm{V}$ is the permeate pure water volume $(\mathrm{L}), \mathrm{A}$ is the effective area of the membrane $\left(11.34 \mathrm{~cm}^{2}\right), \mathrm{T}$ is the permeation time $(\mathrm{h}) . \mathrm{R}$ is the rejection rate of BSA (\%) and $\mathrm{C}_{\mathrm{P}}$ and $\mathrm{C}_{\mathrm{F}}$ are the BSA contents of the feed and the permeate solution (wt. \%), respectively.

\subsubsection{Porosity and pore size}

Membrane porosity $\varepsilon(\%)$ is the ratio of the total volume of pores in the membrane to the bulk volume of the membrane. In this paper, it was determined by the dry-wet weight method [55]. The porosity was calculated as:

$$
\varepsilon=\frac{\left(m_{w}-m_{D}\right) / \rho_{\text {ethanol }}}{\left(m_{W}-m_{D}\right) / \rho_{\text {ethanol }}+m_{D} / \rho_{p}}
$$

where $m_{W}$ is the weight of the wet membrane, $m_{D}$ is the weight of the dry membrane, $\rho_{p}$ is the density of PES $\left(1.370 \mathrm{~g} \cdot \mathrm{cm}^{-3}\right)$, and $\rho_{\text {ethanol }}$ is the density of ethanol $\left(0.790 \mathrm{~g} \cdot \mathrm{cm}^{-3}\right)$.

Mean pore size $\left(\mathrm{r}_{\mathrm{m}}\right)$ was calculated via the filtration velocity method. As described by the Guerout-Elford-Ferry equation [56], $\mathrm{r}_{\mathrm{m}}$ can be expressed by the following equation:

$$
r_{m}=\sqrt{\frac{(2.9-1.75 \varepsilon) \times 8 \eta h Q}{\varepsilon \times A \times \Delta P}}
$$

where $\varepsilon$ is membrane porosity, $\eta$ is the viscosity of water $\left(8.9 \times 10^{-4} \mathrm{~Pa} \cdot \mathrm{s}\right), \mathrm{Q}$ is pure water flux $\left(\mathrm{mL} \cdot \mathrm{s}^{-1}\right)$, $\mathrm{h}$ is membrane thickness $(\mathrm{mm}), \mathrm{A}$ is the effective area of the membrane $\left(11.34 \mathrm{~cm}^{2}\right)$ and $\Delta \mathrm{P}$ is the feed 


\section{ACCEPTED MANUSCRIPT}

pressure $(0.1 \mathrm{MPa})$.

\subsubsection{Mechanical properties}

The tensile strength, Young's modulus and elongation at break of the prepared membranes were measured by a material tensile testing machine (QJ-210A, Shanghai Qingji Instrumentation Science and Technology Co. Ltd., China). The tensile loading speed was $50 \mathrm{~mm} \cdot \mathrm{min}^{-1}$, and the gauge length was $50 \mathrm{~mm}$. Each membrane sample was measured at least three times and then averaged.

\section{Results and discussion}

\subsection{Phase diagram of PES/DMAc/DEG system}

The effects of PES molecular weight on phase separation temperature and viscosity are shown in Table 5. The cloud point showed similar values when PES with significant molecular weights was used. Phase separation of the casting solutions with LCST is mainly induced by decreasing hydrogen-bonding interactions between PES and mixed solvent with an increase in the temperature of the casting solution. The difference in PES molecular weight is not attributed to the hydrogen-bonding interactions. Furthermore, the experimental results confirm that phase separation temperature has little to do with PES molecular weight. In addition, the viscosities of the three casting solutions were shifted to higher viscosities, as the PES molecular weight increased as expected.

The phase diagram and the viscosity for PES/DMAc/DEG systems with different PES contents are shown in Fig. 2, in which it is evident that the cloud point decreased as PES concentration increased. The result can be explained by the intermolecular interaction forces between PES and mixed solvent (DMAc/DEG). In spite of the incompatibility between PES and non-solvent DEG, PES can dissolve in the mixed solvent (DMAc/DEG) and maintain stability at room temperature, which is due to the good compatibility between PES and solvent DMAc. The casting solution is LCST system, meaning 


\section{ACCEPTED MANUSCRIPT}

that hydrogen-bonding interactions change poorly between DMAc and DEG, in line with increasing the temperature of the casting solution. Correspondingly, the apparent concentration of DEG (non-solvent), which does not bond to solvent (DMAc), increases until it is higher than a critical concentration at a certain temperature. At this point, the poor interactions between PES and DEG dominate the casting solution, while DEG separates out as a non-solvent rich phase and PES precipitates from the casting solution.

This indicates that it is easier to induce phase separation at lower temperature, when PES concentration increases. The viscosities are illustrated in Fig. 2, indicating that the viscosity shifts higher as PES concentration increases.

Table 5 Cloud points and viscosities of the PES/DMAc/DEG casting solutions.

\begin{tabular}{cccc}
\hline Casting solutions & Types of PES & $\mathrm{T}_{\mathrm{c}}\left({ }^{\circ} \mathrm{C}\right)$ & Viscosity $(\mathrm{mPa} \cdot \mathrm{s})$ \\
\hline MDEG1-17a & PES51000 & 27 & 1535 \\
MDEG2-17 & PES62000 & 26 & 1689 \\
MDEG3-17 & PES77000 & 26 & 3361 \\
\hline
\end{tabular}

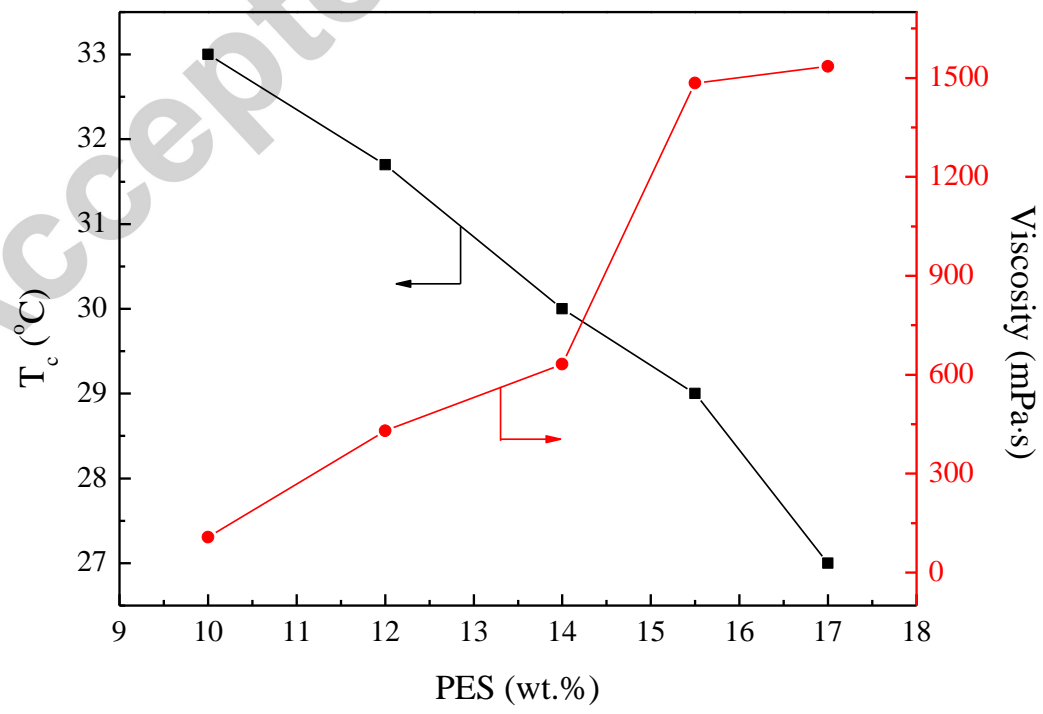

Fig. 2. Phase diagram and viscosity of the PES/DMAc/DEG system. Types of PES: PES51000, 
DEG/DMAc (wt./wt.): 1:1.

\subsection{Estimation of the cloud point for the PES/DMAc/DEG system}

The cloud points of different PES/DMAc/DEG systems were estimated. From equations (1), (2) and (3), the difference in solubility parameters $\left(\Delta \delta_{s-p}\right)$ between the mixed solvent and PES was calculated and is listed in Table 6 . It is evident that the $\delta_{\mathrm{H}}$ increases when increasing the mass ratio of DEG/DMAc, whereas $\delta_{\mathrm{D}}$ and $\delta_{\mathrm{P}}$ change very little, thereby indicating that the interactions between PES and mixed solvent are influenced mainly by a hydrogen-bonding interaction. Fig. 3 shows the experimental cloud point temperatures for the casting solutions of PES in DEG/DMAc, and it is notable that the cloud points decrease in line with the increase in $\Delta \delta_{\text {s-p. }}$ In addition, there is a good linear relationship $\left(r^{2}=0.9980\right)$ between the experimental cloud points and the $\Delta \delta_{\mathrm{s}-\mathrm{p}}$, and the linear regression of the data gives the relation:

$\mathrm{T}_{\mathrm{c}}=89.5-9.1 \Delta \delta_{\mathrm{s}-\mathrm{p}}$

where $T_{\mathrm{c}}$ is the cloud point.

From Fig. 3, the experimental results show fair agreement with the linear regression line, thereby suggesting that the mass ratio of DEG/DMAc can be conveniently adjusted to control the phase separation temperature. Based on the experiments and estimations, it is evident that the mass ratio of DEG/DMAc can be applied as a key processing parameter for controlling the thermodynamic properties of casting solutions and provides the necessary theoretical basis for PES membrane preparation via the RITPS method. 
Table 6 Solubility parameters for PES and mixed solvent.

\begin{tabular}{ccccccc}
\hline PES and mixed solvent & $\begin{array}{c}\text { DEG:DMAc } \\
\text { (wt.:wt. })\end{array}$ & $\delta_{\mathrm{D}} / \mathrm{MPa}^{1 / 2}$ & $\delta_{\mathrm{P}} / \mathrm{MPa}^{1 / 2}$ & $\delta_{\mathrm{H}} / \mathrm{MPa}^{1 / 2}$ & $\delta_{\mathrm{t}} / \mathrm{MPa}^{1 / 2}$ & $\Delta \delta_{\text {s-p }} / \mathrm{MPa}^{1 / 2}$ \\
\hline PES & - & 17.60 & 10.40 & 7.80 & 21.90 & - \\
DEG/DMAc & $0.7: 1$ & 16.75 & 11.62 & 12.82 & 24.08 & 5.23 \\
DEG/DMAc & $0.75: 1$ & 16.74 & 11.64 & 13.14 & 24.26 & 5.55 \\
DEG/DMAc & $0.8: 1$ & 16.74 & 11.65 & 13.44 & 24.42 & 5.84 \\
DEG/DMAc & $0.9: 1$ & 16.73 & 11.68 & 13.89 & 24.68 & 6.28 \\
DEG/DMAc & $0.95: 1$ & 16.72 & 11.69 & 14.22 & 24.87 & 6.61 \\
DEG/DMAc & $1: 1$ & 16.72 & 11.70 & 14.48 & 25.03 & 6.86 \\
\hline
\end{tabular}

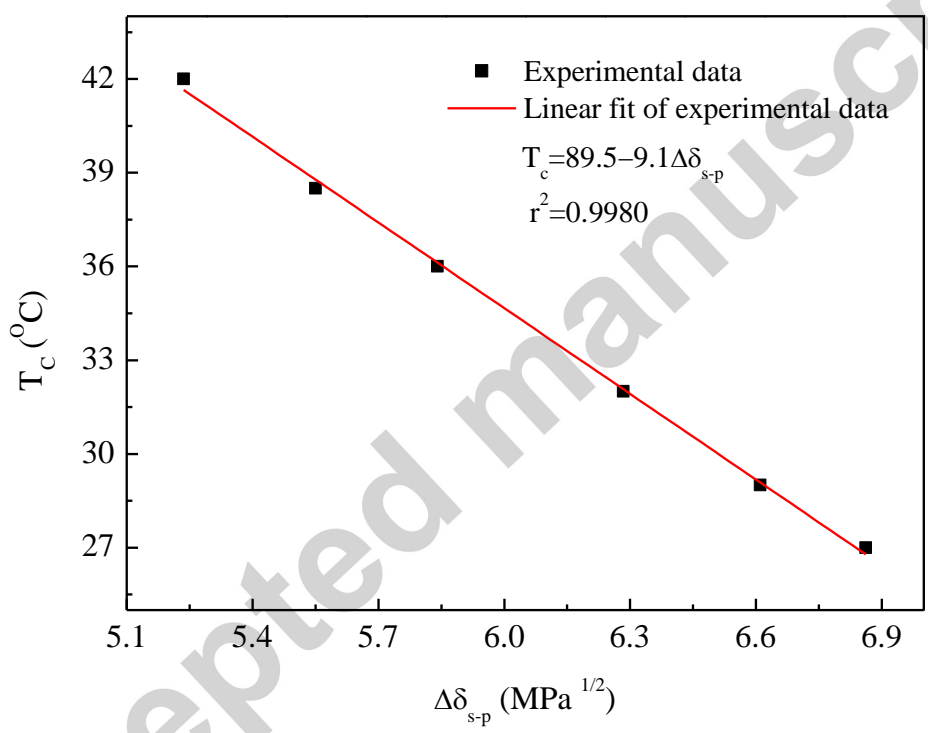

Fig. 3. Relationship between $\Delta \delta_{s-p}$ and cloud points for the PES/DMAc/DEG system. The concentration of PES is $17 \mathrm{wt} . \%$.

\subsection{Cloud points of PES/DMAc/PEG systems}

The effects of PEG molecular weight and mass ratio of non-solvent/solvent (PEG/DMAc) on cloud point are shown in Fig. 4. Firstly, for PES/DMAc/PEG200, PES/DMAc/PEG300 and PES/DMAc/PEG400 systems, the cloud points showed similar trend of decreased cloud point with an increase of mass ratio of PEG/DMAc. The reason for this is the same as that of the PES/DMAc/DEG 


\section{ACCEPTED MANUSCRIPT}

systems. Due to good compatibility between PES and DMAc, PES can dissolve in the mixed solvent (DMAc/PEG) and keep stability at room temperature in spite of the incompatibility between PES and PEG (non-solvent). When the amount of PEG increases, the interactions between PES and the mixed solvent become weaker, and consequently the casting solution is easier to induce phase separation within at lower temperature. This indicates that the cloud point can be controlled by the mass ratio of non-solvent/solvent.

Secondly, it is obvious that the cloud point increases with increasing the PEG molecular weight. From the data in Table 3, it can be seen that the $\Delta \delta_{\text {s-p }}$ between PES and PEG decreases when the PEG molecular weight increases. This means that the intermolecular interaction forces between PES and mixed solvent become stronger as PEG molecular weight increases. Thus, phase separation of the casting solution will occur at higher temperature.

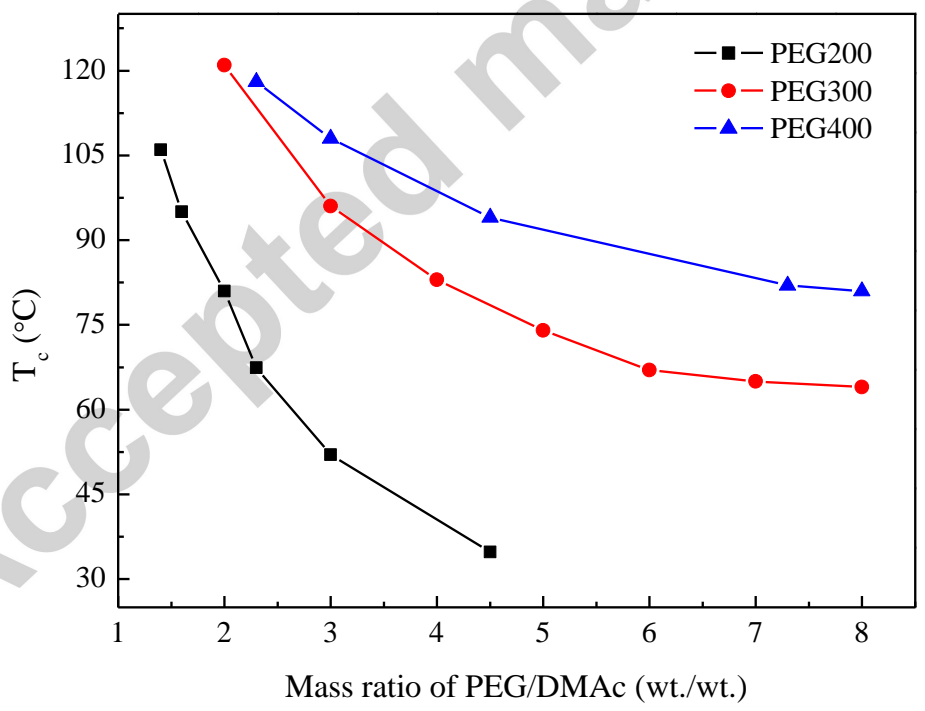

Fig. 4. Cloud points of different PES/DMAc/PEG systems.

\subsection{Estimation of the cloud point for the PES/DMAc/PEG system}

The cloud points of PES/DMAc/PES200, PES/DMAc/PEG300 and PES/DMAc/PEG400 systems were estimated, respectively. $\Delta \delta_{\text {s-p }}$ between the mixed solvent (PEG200/DMAc, PEG300/DMAc and 


\section{ACCEPTED MANUSCRIPT}

PEG400/DAMc) and PES was calculated and is listed in Table 7. From the data in Table 7, it can be seen that $\delta_{\mathrm{H}}$ increases and $\delta_{\mathrm{P}}$ decreases when increasing the mass ratio of PEG200/DMAc, whereas $\delta_{\mathrm{D}}$ changes only a little. The PEG/DMAc/PEG300 and PES/DMAc/PEG400 systems have the same pattern as the PES/DMAc/PEG200 systems. These observations indicate that the interactions between PES and mixed solvent are controlled by dipolar and hydrogen interactions.

Fig. 5 shows the experimental cloud points for the PES/DMAc/PES200, PES/DMAc/PEG300 and PES/DMAc/PEG400 casting solutions, and it is evident that the cloud points decrease when increasing $\Delta \delta_{\text {s-p }}$. There is a good linear relationship between the experimental cloud point and $\Delta \delta_{\text {s-p }}$, and the linear regression equations of the data are listed in Table 8 . These linear relationships indicate that the mass ratios of PEG200/DMAc, PEG300/DMAc and PEG400/DMAc in a simple way can be used to control the cloud point. It is evident that the mass ratio of non-solvent/solvent (PEG/DMAc) is a key processing parameter for controlling the thermodynamics of the casting solutions and is applied as a theoretical estimation of phase separation temperature for the PES membrane preparation via RITPS method.

Furthermore, it can be seen that the linear regression line shifts to higher cloud points as the PEG molecular weight increases from 200 to 300 . When the PEG molecular weight further increases from 300 to 400 , the shift of the linear regression line is not obvious. The difference is, however, attributed to the difference of $\Delta \delta_{\text {s-p }}$ between PES and PEG200, PEG300 and PEG400. From the data in Table 3, it can be seen that $\delta_{\mathrm{H}}$ and $\delta_{\mathrm{P}}$ decrease when increasing the PEG molecular weight, whereas $\delta_{\mathrm{D}}$ changes only a little. This observation indicates that the molecular interactions between PES and PEG are controlled by dipolar and hydrogen interactions. As shown in Table 7 , the difference of $\Delta \delta_{\text {s-p }}$ is 1.21 when the PEG molecular weight increases from 200 to 300 , and the difference of $\Delta \delta_{\text {s-p }}$ is 0.43 when 


\section{ACCEPTED MANUSCRIPT}

the PEG molecular weight increases from 300 to 400. This means that the effects of PEG molecular weight on intermolecular interaction forces between PES and mixed solvent become weaker as PEG molecular weight increases. Thus, the shift of the linear regression line is an interplay between several factors.

Table 7 Solubility parameters of PES and mixed solvent.

\begin{tabular}{ccccccc}
\hline PES and mixed & $\begin{array}{c}\text { PEG200:DMAc } \\
\text { solvent }\end{array}$ & $\begin{array}{c}\delta_{\mathrm{D}} / \mathrm{MPa}^{1 / 2} \\
\text { wt.:wt. })\end{array}$ & $\delta_{\mathrm{P}} / \mathrm{MPa}^{1 / 2}$ & $\delta_{\mathrm{H}} / \mathrm{MPa}^{1 / 2}$ & $\delta_{\mathrm{t}} / \mathrm{MPa}^{1 / 2}$ & $\Delta \delta_{\text {s-p }} / \mathrm{MPa}^{1 / 2}$ \\
\hline PEG200/DMAc & $1.4: 1$ & 17.27 & 9.29 & 13.08 & 23.58 & 5.41 \\
PEG200/DMAc & $1.6: 1$ & 17.36 & 8.90 & 13.60 & 23.78 & 5.99 \\
PEG200/DMAc & $2: 1$ & 17.49 & 8.29 & 14.39 & 24.12 & 6.92 \\
PEG200/DMAc & $2.3: 1$ & 17.57 & 7.91 & 14.89 & 24.35 & 7.51 \\
PEG200/DMAc & $3: 1$ & 17.70 & 7.34 & 15.63 & 24.72 & 8.41 \\
PEG200/DMAc & $4.5: 1$ & 17.83 & 6.71 & 16.46 & 25.18 & 9.42 \\
PEG300/DMAc & $2: 1$ & 17.34 & 8.18 & 12.60 & 22.94 & 5.29 \\
PEG300/DMAc & $3: 1$ & 17.55 & 6.87 & 13.55 & 23.21 & 6.75 \\
PEG300/DMAc & $4: 1$ & 17.67 & 6.12 & 14.08 & 23.41 & 7.60 \\
PEG300/DMAc & $5: 1$ & 17.74 & 5.69 & 14.39 & 23.55 & 8.10 \\
PEG300/DMAc & $6: 1$ & 17.78 & 5.43 & 14.58 & 23.63 & 8.41 \\
PEG300/DMAc & $7: 1$ & 17.81 & 5.26 & 14.71 & 23.69 & 8.61 \\
PEG300/DMAc & $8: 1$ & 17.83 & 5.14 & 14.79 & 23.73 & 8.75 \\
PEG400/DMAc & $2.3: 1$ & 17.33 & 7.80 & 12.00 & 22.48 & 4.95 \\
PEG400/DMAc & $3: 1$ & 17.47 & 6.86 & 12.46 & 22.53 & 5.85 \\
PEG400/DMAc & $4.5: 1$ & 17.65 & 5.59 & 13.08 & 22.67 & 7.14 \\
PEG400/DMAc & $7.3: 1$ & 17.78 & 4.71 & 13.51 & 22.82 & 8.06 \\
PEG400/DMAc & $8: 1$ & 17.79 & 4.60 & 13.56 & 22.84 & 8.18 \\
\hline
\end{tabular}




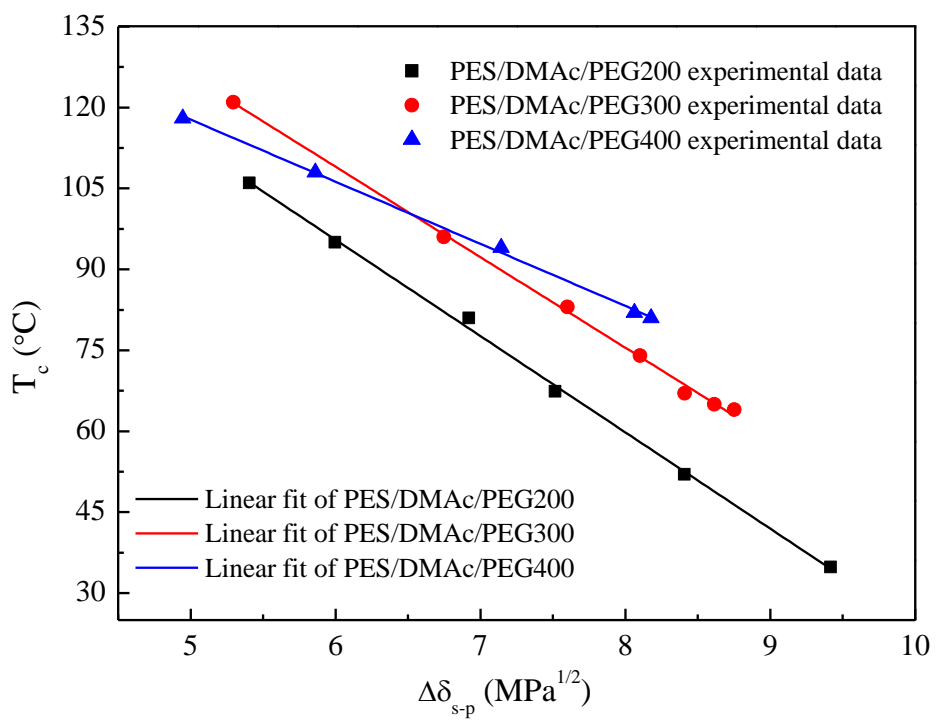

Fig. 5. Relationship between $\Delta \delta_{\text {s-p }}$ and cloud points for the PES/DMAc/PEG system. The concentration of PES is $17 \mathrm{wt} . \%$.

Table 8 Linear regression equations of different PES/DMAc/PEG systems.

\begin{tabular}{ccc}
\hline System & Linear regression equation & $\mathrm{r}^{2}$ \\
\hline PES/DMAc/PEG200 & $\mathrm{T}_{\mathrm{c}}=202.6-17.8 \Delta \delta_{\mathrm{s}-\mathrm{p}}$ & 0.9981 \\
PES/DMAc/PEG300 & $\mathrm{T}_{\mathrm{c}}=208.5-16.6 \Delta \delta_{\mathrm{s}-\mathrm{p}}$ & 0.9924 \\
PES/DMAc/PEG400 & $\mathrm{T}_{\mathrm{c}}=175.3-11.5 \Delta \delta_{\mathrm{s}-\mathrm{p}}$ & 0.9984 \\
\hline
\end{tabular}

In addition, the viscosities of different PES/DMAc/PEG systems are shown in Fig.6, showing that the viscosity increases as PEG molecular weight and $\Delta \delta_{\mathrm{s}-\mathrm{p}}$ (mass ratio of non-solvent/solvent) increase. Combining with Fig. 4 and Fig. 6, it can be seen that if the molecular weight of PEG continues to increase, the cloud point and viscosity of the casting solution will increase and the membrane formation process is difficult to operate. 


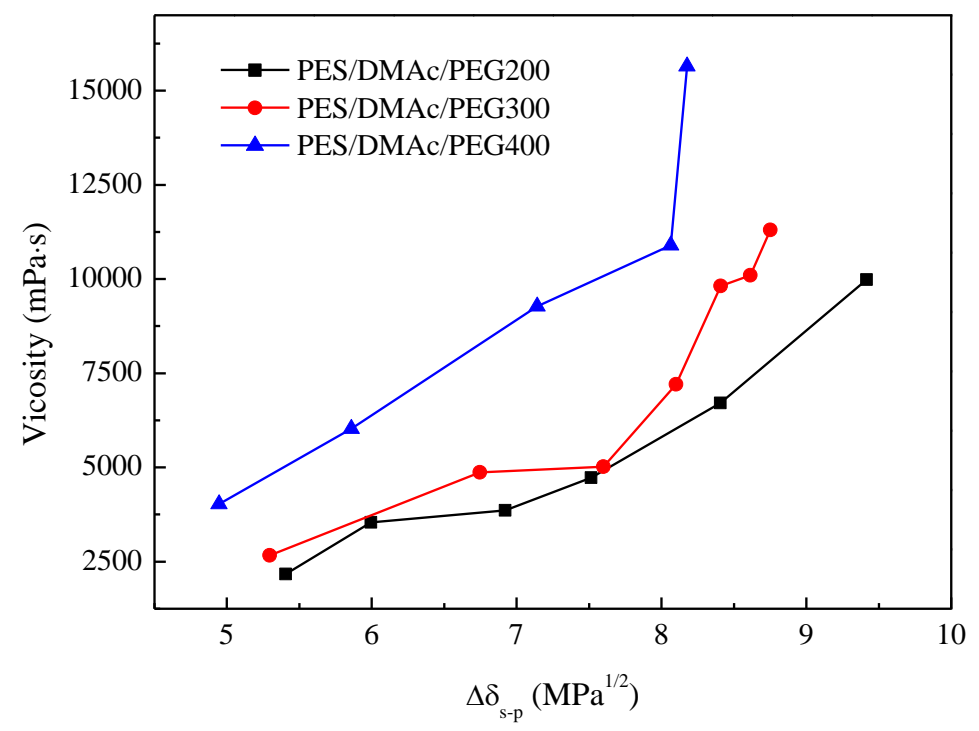

Fig. 6. Viscosities of different PES/DMAc/PEG systems.

In general, based on the above discussion, it is evident that by changing the mass ratio of a non-solvent/solvent or PEG molecular weight, the phase separation temperature can be estimated, which in turn can provide theoretical guidance for PES membrane preparation via the RITPS method. The method allows for a quick estimation of the cloud point.

\subsection{Membrane morphology}

The SEM micrographs of PES flat sheet membranes, prepared by the NIPS and RTIPS processes, are shown in Fig. 7. The cloud point of the casting solution MDEG1-12 is $31.7^{\circ} \mathrm{C}$. When the water bath temperature was $20^{\circ} \mathrm{C}$, which was lower than the cloud point, the membrane formation process was dominated by the NIPS process. The membrane MDEG1-12-20, with finger-like pores, was formed in the cross-section, and instantaneous demixing was induced by the inflow of pure water, as shown in Fig.8. When the water bath temperature was $50^{\circ} \mathrm{C}$, which is higher than the cloud point, the membrane formation process was dominated by the RTIPS mechanism. Membrane MDEG1-12-50 with a bi-continuous structure was prepared, representing the typical morphology of membranes with 


\section{ACCEPTED MANUSCRIPT}

high flux, as shown in Fig.8. Since the membrane formation process is induced by the formation of a translucent membrane via mass traansfer or heater transfer, the velocity of light transmittance changes is directly related to the phase separation rate. To understand the difference between the heat transfer rate and mass transfer rate, light transmittance experiments were conducted. As shown in Fig. 9, the light transmittance of casting solution MDEG1-12 at $20^{\circ} \mathrm{C}$ changed more rapidly than that of the casting solution MDEG1-15.5 at $20^{\circ} \mathrm{C}$. This is due to the water bath temperature being $20^{\circ} \mathrm{C}$, which was lower than the cloud point, and the casting solution MDEG1-12 possesses the low viscosity (as shown in Fig. 2), which means fast mass transfer. Thus the NIPS process is the dominating membrane formation process and finger-like pore was formed. Meanwhile, when the water bath tempeature was $50^{\circ} \mathrm{C}$, which is higher than the cloud point, the slope of the initial part of the light transmittance curve for the casting solution MDEG1-12 and MDEG1-15.5 increase rapidly and there is no slope difference between the two casting solutions. If the NIPS is the dominating process, the phase separation rate of MDEG1-15.5 should be lower than that of MDEG1-12. The observation indicates that the phase rate of heat transfer is independent of the viscosity. This comfirmed that the heat tranfer rate is much faster than the mass transfer rate and RTIPS is the dominating process. Thus, heat transfer is the major driving force of membrane formation when the temperature is higher than the cloud point, which results in the formation of a bi-continuous structure.
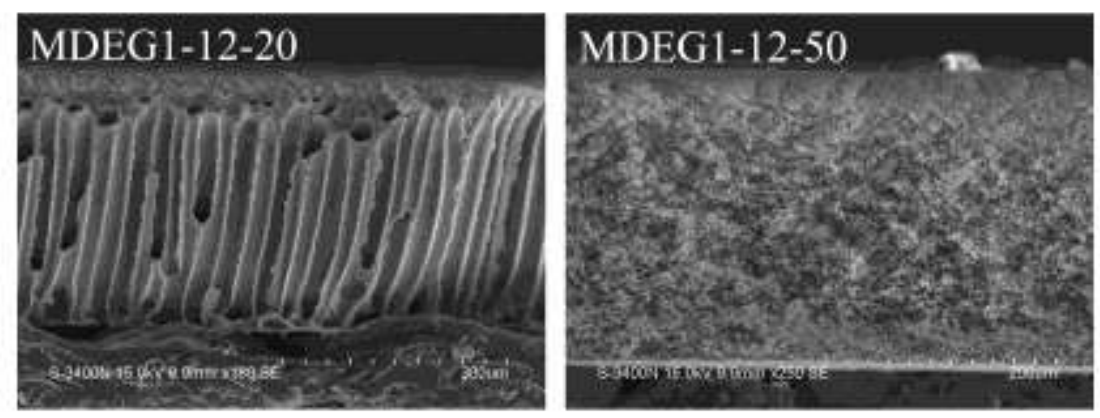

Fig. 7. SEM micrographs of PES flat sheet membrane cross-sections. 


\section{ACCEPTED MANUSCRIPT}

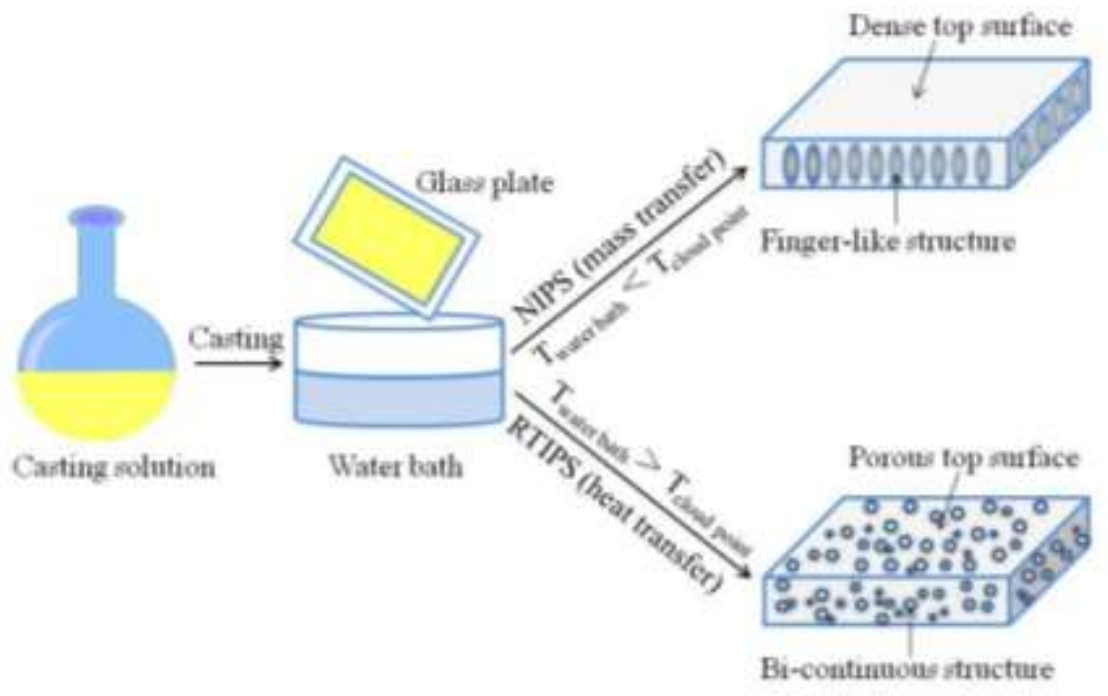

Fig. 8 Schematic diagram of membrane formation for NIPS and RTIPS method.

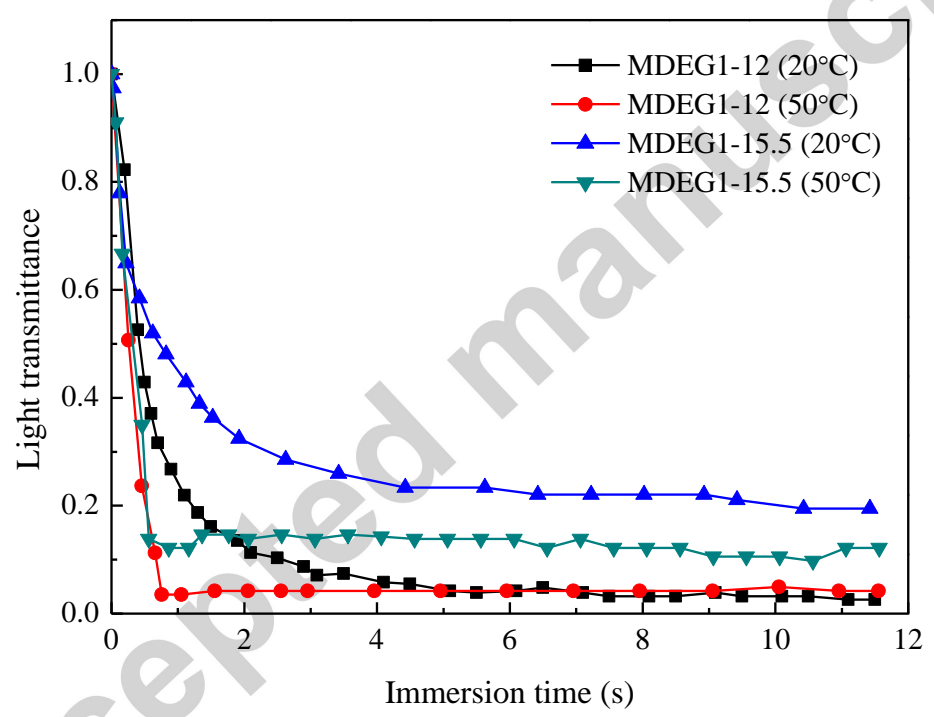

Fig. 9. Light transmittance curves of casting solutions.

SEM images of PES membranes prepared with different PES contents via the RTIPS process are shown in Fig. 10. As shown in Fig. 2, the cloud points of the casting solutions with different PES contents are between $27^{\circ} \mathrm{C}$ and $33^{\circ} \mathrm{C}$. When the membrane formation temperature is $50^{\circ} \mathrm{C}$, which is higher than the cloud points, the membrane formation process is controlled by the RTIPS mechanism, because of the main driving force of phase separation being heat transfer instead of mass transfer. All 


\section{ACCEPTED MANUSCRIPT}

the membranes are presented as a bi-continuous structure, as shown in Fig. 10, which confirms the membrane-forming mechanism is RTIPS process $[48,51]$.
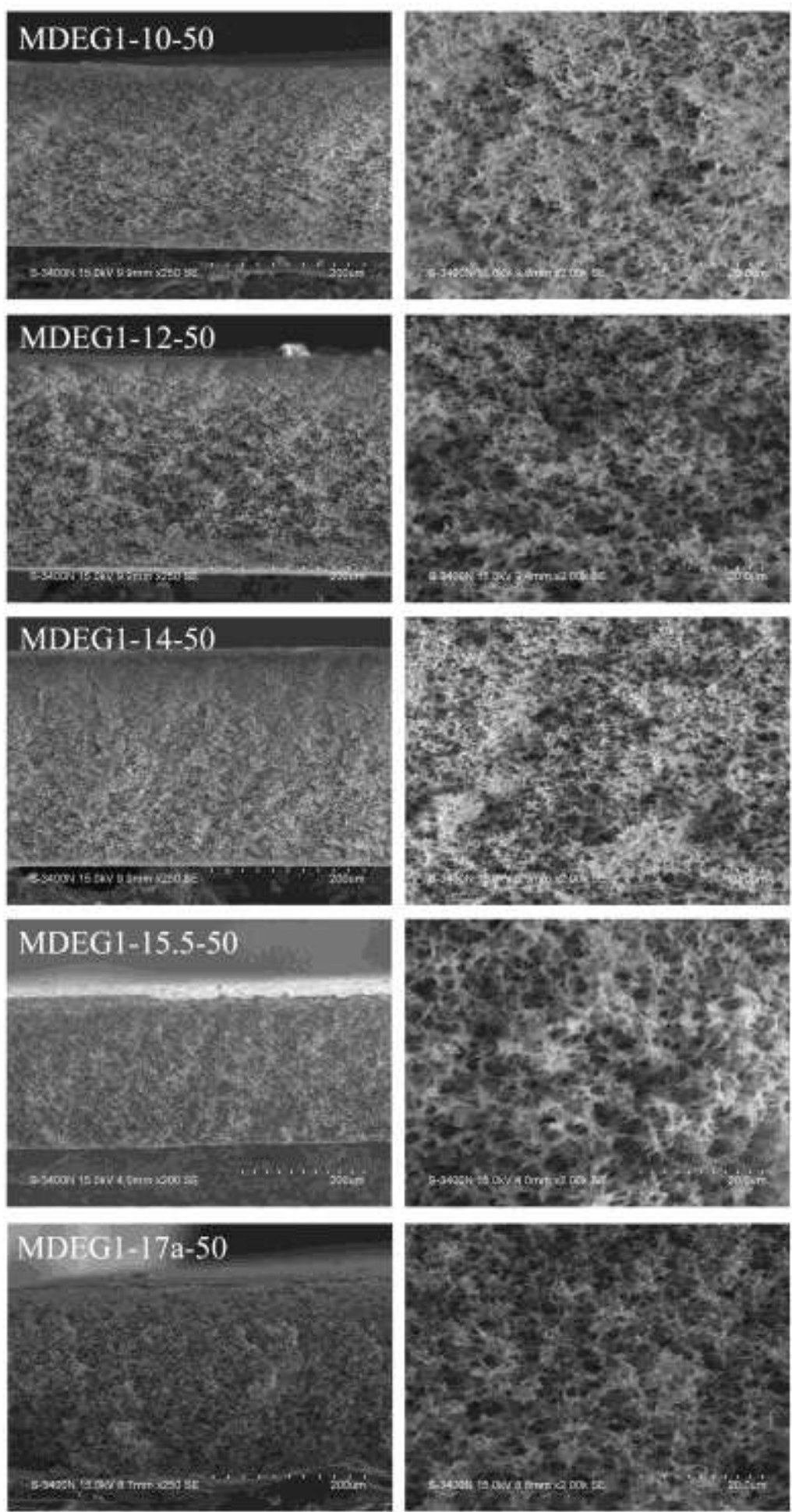

Fig. 10 SEM micrographs of PES flat sheet membrane cross-sections prepared via the RTIPS process.

(L) Cross-section and (R) enlarge cross-section. 


\section{ACCEPTED MANUSCRIPT}

The SEM micrographs of PES membranes prepared with different PEG molecular weights via the NIPS and RTIPS processes are shown in Fig. 11. As shown in Fig. 4, the cloud point of the casting solution MPEG200-4 is $67.4^{\circ} \mathrm{C}$. When the water bath temperature was $20^{\circ} \mathrm{C}$, which was lower than the cloud point, NIPS was the dominating process and the membrane MPEG200-4-20 with finger-like pores was formed in the cross-section. When the water bath temperature was $80^{\circ} \mathrm{C}$, which was higher than the cloud point, RTIPS was the dominated process and the membrane MPEG200-4-80 with bi-continuous structure was presented. The cloud point of the casting solution MPEG300-4 is $67.0^{\circ} \mathrm{C}$.

Similarly, when the membrane formation temperature is $50^{\circ} \mathrm{C}$, which is lower than the cloud point, the membrane formation process is controlled by the NIPS mechanism. Membrane MPEG300-4-50 with a finger-like pore resulted. When the membrane formation temperature is $80^{\circ} \mathrm{C}$, which is higher than the clout point, the membrane MPEG300-4-80 with a bi-continuous structure was formed.
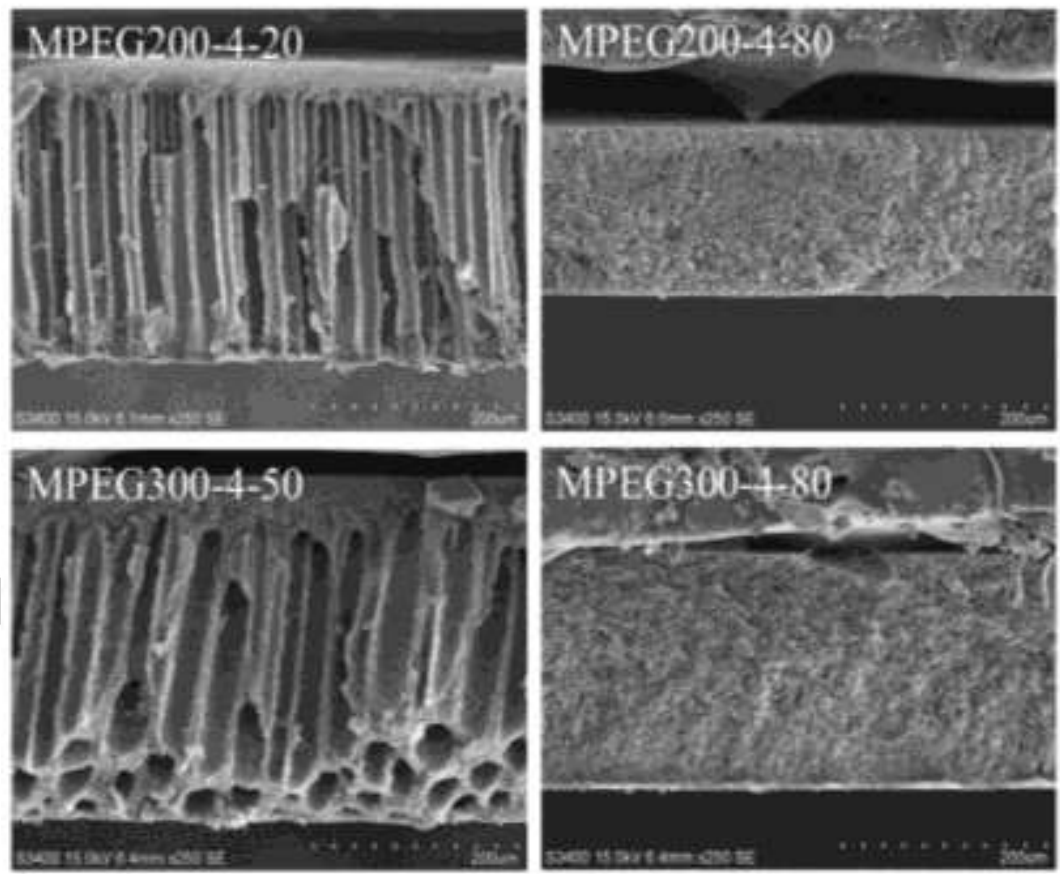

Fig. 11. SEM micrographs of PES flat sheet membrane cross-sections prepared with different PEG molecular weights.

In summary, based on the above SEM results, it is evident that a change in the membrane formation 


\section{ACCEPTED MANUSCRIPT}

mechanism and the control of membrane structure have been relised by changing only the membrane-forming temperature.

\subsection{Permeation properties, porosity and pore size}

The determined permeation parameters, the porosity and mean pore size of PES membranes prepared with different PES concentration, water bath temperature and mixed solvent, are shown in Fig. 12 and Fig. 13. Firstly, for MDEG1-12-50, MPEG200-4-80 and MPEG300-4-80, the membrane formation mechanism is the RTIPS process, and $\mathbf{J}_{\mathrm{w}}$ is higher than for the corresponding membranes (MDEG1-12-20, MPEG200-4-20 and MPEG300-4-50) prepared by the NIPS process (see Fig. 12a and Fig. 12d). As shown in Fig. 13(a), the MDEG1-12-50 membrane has a smaller $r_{m}$ than that of the MDEG1-12-20 membrane, so the rejection rate of the membrane MDEG1-12-50 is a higher value (see Fig. 12a). From Fig. 13(d), it is notable that the MPEG200-4-80 and MPEG300-4-80 membranes, which are prepared by the RTIPS process, have a larger $r_{m}$ and rejection rate $(R)$ than the corresponding membranes (MPEG200-4-20 and MPEG300-4-50) prepared with the NIPS process. Based on these experiments, it can be seen clearly that PES membranes prepared by the RTIPS method can be applied as a new tool for preparing membranes with high flux and a high rejection rate, thereby reflecting the advantages of RTIPS method.

However, for the MDEG1-10-50 membrane, $\mathrm{J}_{\mathrm{w}}$ is $126 \mathrm{~L} \cdot \mathrm{m}^{-2} \cdot \mathrm{h}^{-1}$, which is less than the value of 299 $\mathrm{L} \cdot \mathrm{m}^{-2} \cdot \mathrm{h}^{-1}$ of the MDEG1-10-20 membrane, as shown in Fig. 12(a). According to the experimental results, it is evident that the membrane MDEG1-10-50 (prepared by the RTIPS process) has lower pure water flux than that of MDEG1-10-20 membrane prepared by employing the NIPS process. The result is inconsistent with the advantages of the RTIPS method for preparing high flux membranes. According to the membrane-forming mechanism of RTIPS, when the membrane-forming temperature 


\section{ACCEPTED MANUSCRIPT}

$\left(50^{\circ} \mathrm{C}\right)$ is higher than the cloud point $\left(33^{\circ} \mathrm{C}\right)$ of the casting solution, the membrane formation mechanism should be dominated by the RTIPS process. Membrane MDEG1-10-50 with a bi-continuous structure was prepared indeed (Fig. 10). In reality, the PES concentration of the casting solution MDEG1-10 is low (10 wt.\%, ), the tensile strength of the membrane MDEG1-10-20 is poor (0.4 MPa, as shown in Fig. 13). The finger-like pore membrane prepared at low PES concentration is more vulnerable to damage under the test pressure. Therefore, the membrane MDEG1-10-20 showed higher apparent $\mathbf{J}_{\mathrm{w}}$ and $\mathrm{r}_{\mathrm{m}}$.

Secondly, the $\mathrm{J}_{\mathrm{w}}$ of the membranes prepared by the RTIPS process reaches peak value for the MDEG1-14-50 membrane following an increase in PES concentration (see Fig. 12b), because the viscosity of the MDEG1-14 casting solution is great enough for phase separation via RTIPS and lower than the viscosities of the casting solutions MDEG1-15.5 and MDEG1-17. The phase separation rate between PES-rich phase and PES-poor phase is influenced by the viscosity of the casting solution and reaches equilibrium at 14 wt.\%. Thus, the MDEG1-14-50membrane has good pore connectivity, which is embodied in a maximum $r_{m}$ value (see Fig. 13d). In addition, the porosity of the membranes prepared by the RTIPS process decreases in line with an increase in PES concentration, as shown in Fig. 13(b), due to an increase in solid content.

Thirdly, the $\mathbf{J}_{\mathrm{w}}$ and $\mathrm{r}_{\mathrm{m}}$ of membranes prepared via the RTIPS process in Fig. 12 and Fig. 13 present a downtrend in line with an increase in PES molecular weights in the following descending order: MDEG1-17a-50, MDEG2-17-50 and MDEG3-17-50. The reason for this can be attributed mainly to viscosity differences in the casting solutions. Higher viscosity means a lower rate of phase separation. Accordingly, $r_{m}$ is small. From the results in Fig. 13(c) it can be seen clearly that the porosity $(\varepsilon)$ remains almost constant. 


\section{ACCEPTED MANUSCRIPT}
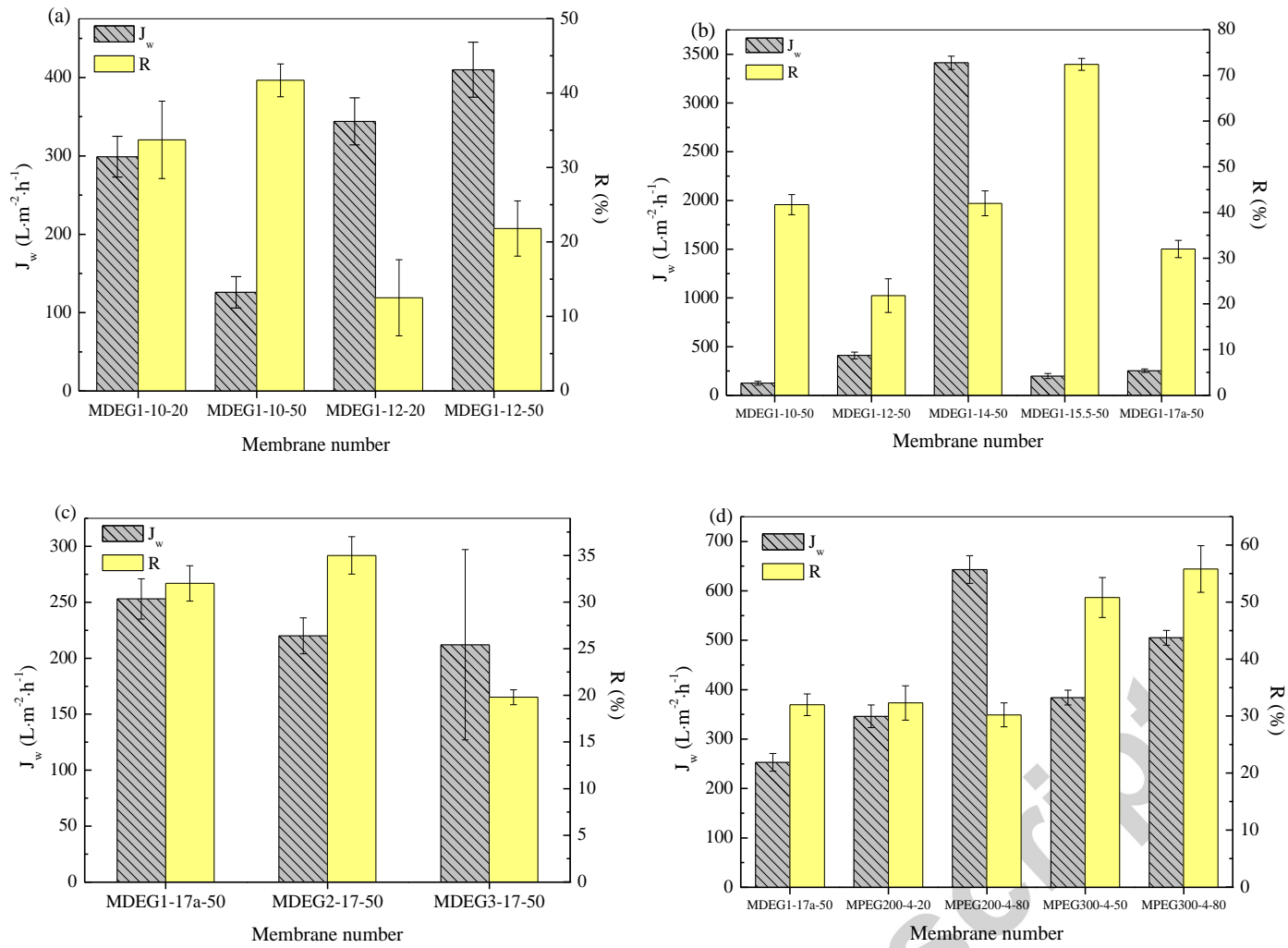

Fig. 12. Pure water permeation flux and rejection rate of the prepared PES membranes.
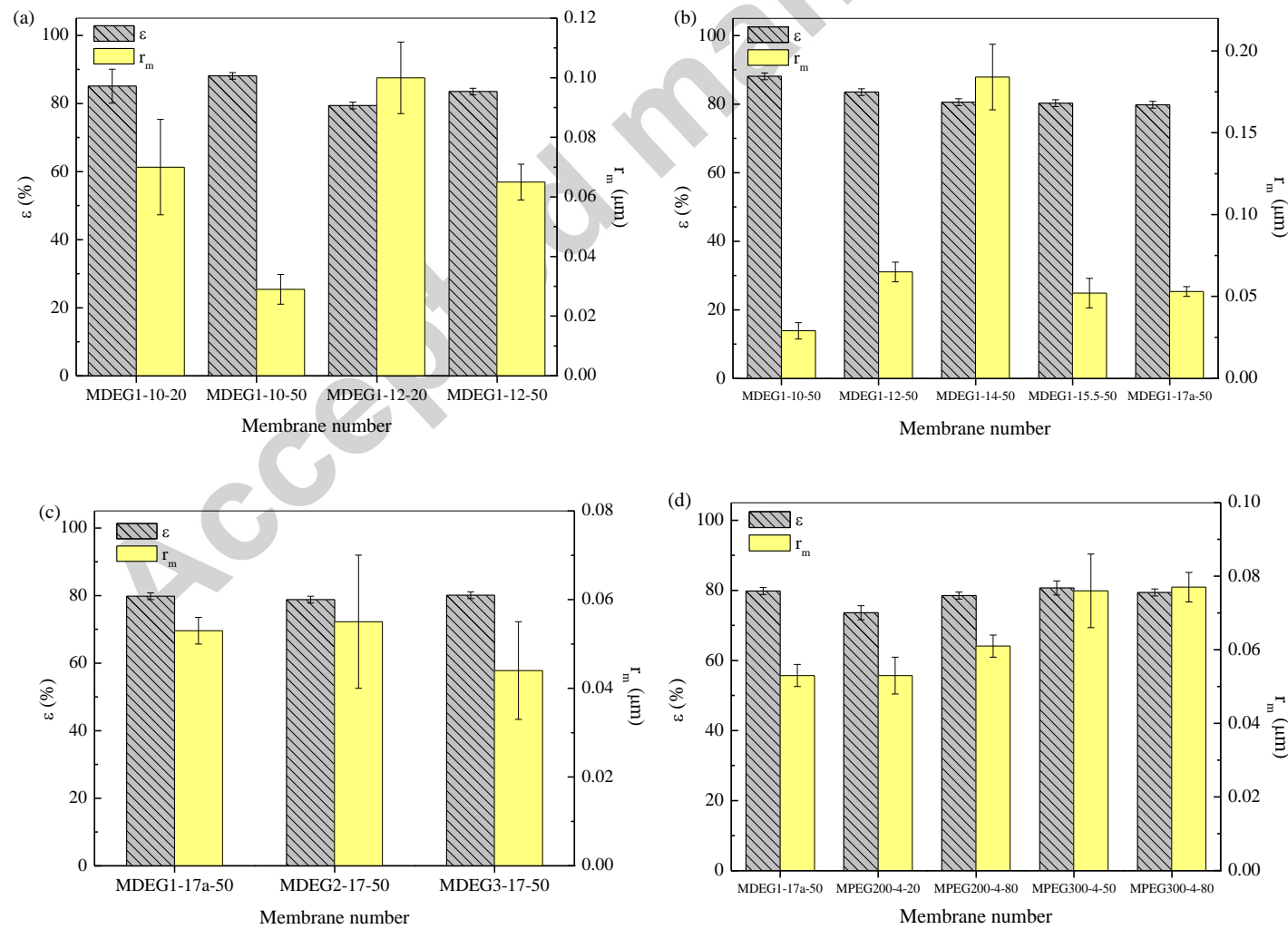

Fig. 13. Porosity and mean pore size of the prepared PES membranes. 


\section{ACCEPTED MANUSCRIPT}

\subsection{Mechanical properties}

The mechanical properties of PES membranes prepared with different PES concentration, water bath temperatures and mixed solvent are presented in Fig. 14. For MDEG1-10-20, MDEG1-12-20, MPEG200-4-20 and MPEG300-4-50, the membrane formation mechanism is the NIPS process, in which the tensile strength, elongation at break and the Young's modulus are lower than for the corresponding membranes (MDEG1-10-50, MDEG1-12-50, MPEG200-4-80 and MPEG300-4-80), which are prepared with the RTIPS process (see Fig. 14a and Fig. 14d). As shown in Fig. 7, Fig. 10 and Fig. 11, the membrane morphology changes from a finger-like pore structure to a bi-continuous structure when the water bath temperature is higher than the cloud point, and these results in an improvement to the mechanical properties of the membrane.

As Fig. 14(b) shows, the tensile strength and the elongation at break of the membranes prepared with the RTIPS process increase in line with PES content in the following ascending order: MDEG1-10-50, MDEG1-12-50 and MDEG1-14-50. The membrane structure becomes dense following an increase in PES content, which results in an increase in tensile strength and elongation at break. The tensile strength and the elongation at break reached their peak values at 17 wt.\% PES content. Furthermore, Fig. 14(c) shows that the tensile strength and the Young's modulus of the membranes MDEG1-17a-50, MDEG2-17-50 and MDEG3-17-50 increase in line with an increase in PES molecular weight. This indicates that the strength and the stiffness of the membranes were enhanced with the increase in PES molecular weight, which is common behavior for polymers.

The membrane MDEG1-17a-50, which was prepared from a mixed solvent of DEG/DMAc, showed higher tensile strength and elongation at break than the membranes MPEG200-4-80 and MPEG300-4-80, which were prepared from PEG200/DMAc or PEG300/DMAc mixed solvent (seen 


\section{ACCEPTED MANUSCRIPT}

Fig. 14d). This result may be due to the molecular weights of PEG200 and PEG300, which are much greater than DEG. A small amount of PEG200 or PEG300 embedded in the membrane may result in a decrease in tensile strength and elongation at break due to plasticisation effects.
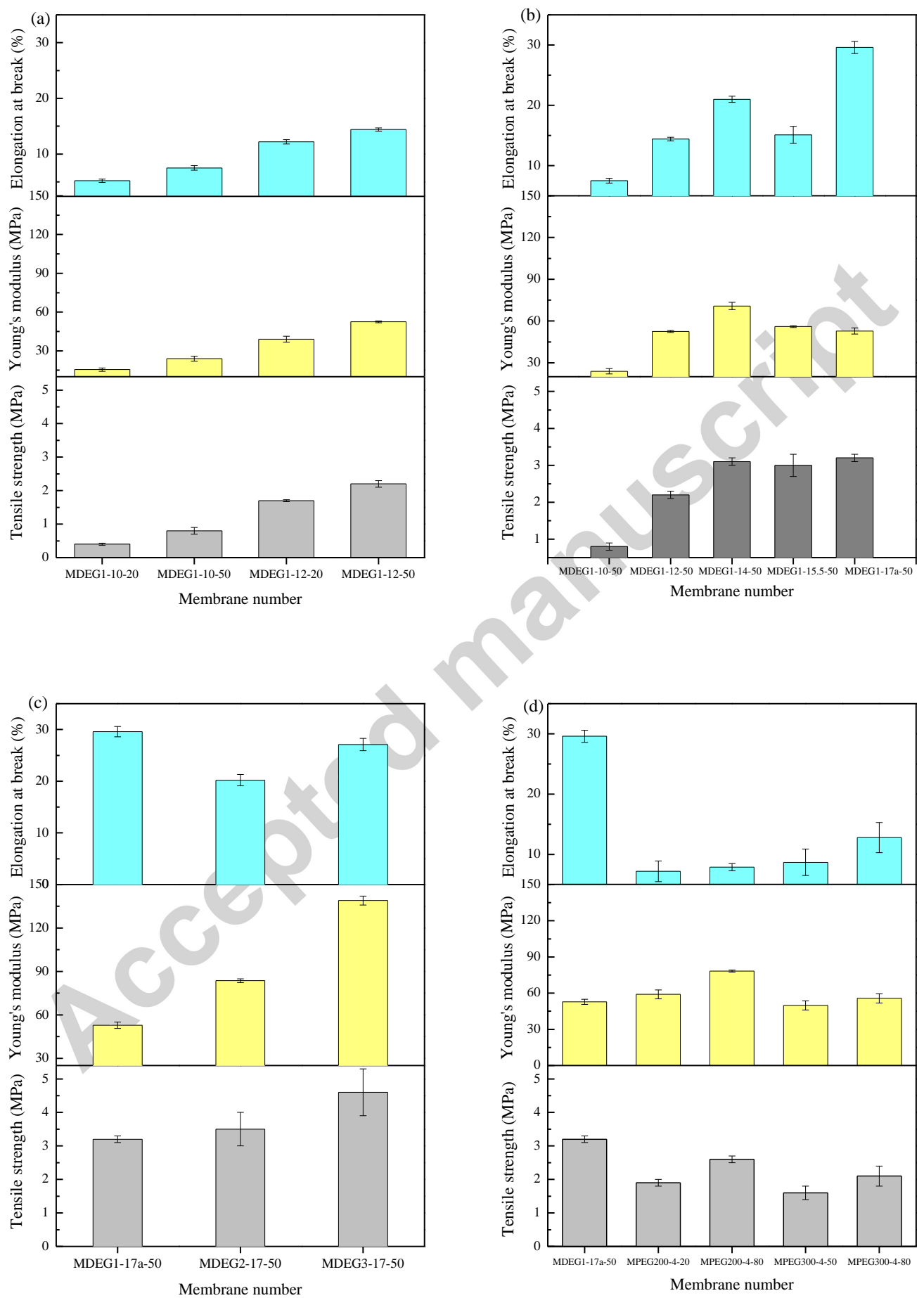

Fig. 14. Mechanical properties of PES membranes. 


\section{ACCEPTED MANUSCRIPT}

\section{Conclusions}

An estimation of phase separation temperature, based on the Hansen solubility parameter, was performed, and then PES flat membranes were prepared via an RTIPS process. As for casting solutions, DMAc was used as the solvent, while DEG, PEG200, PEG300 and PEG400 were used as the non-solvent. The PES/solvent/non-solvent casting solutions were LCST systems, and the cloud point was shown to be independent of PES molecular weight. With the increase in PES content, the cloud point of the prepared casting solutions decreased and the viscosities increased. When the PEG molecular weight increases, the cloud point and the viscosities of the casting solution increased. The calculated Hansen solubility parameters show that there is a good linear relationship between the experimental cloud points and the $\Delta \delta_{\text {s-p. }}$. The composition and membrane-forming temperature of the casting solution are the key casting parameters for PES membrane preparation via the RITPS process, and they can be adjusted according to the requirements.

On the one hand, when the membrane-forming temperature was lower than the cloud point, the membrane formation mechanism was the NIPS process. A finger-like pore structure was present in the membrane. On the other hand, when the membrane-forming temperature was higher than the cloud point, the membrane formation mechanism was mainly dominated by the RTIPS process, and a bi-continuous structure was found in the membranes. Those membranes prepared by employing the RTIPS process exhibited higher pure water permeation flux than that of the membranes prepared with the NIPS process, except for the MDEG1-10-50membrane. The porosity of the membranes prepared by the RTIPS method decreased with an increase in PES concentration, while pure water permeation flux and the mean pore size of membranes prepared by the RTIPS process decreased in line with an increase in PES molecular weight. The advantages of the RTIPS method are reflected by the relatively 


\section{ACCEPTED MANUSCRIPT}

high flux and high rejection rate compared to the NIPS method.

With the increase in PES molecular weight and content, membrane strength improved. Membranes prepared by the DEG/DMAc mixed solvent, showed higher tensile strength and elongation at break than for membranes produced by a PEG200/DMAc or PEG300/DMAc mixed solvent. When the membrane formation mechanism was the RTIPS process, tensile strength, the elongation at break and the Young's modulus were higher than for the corresponding membranes prepared by the NIPS process. It is concluded that the advantage of the RTIPS process is the easy preparation of membranes with symmetrical bi-continuous morphology resulting in good mechanical properties.

\section{Acknowledgements}

The authors are thankful for the financial support of the China Scholarship Council and the National Natural Science Foundation of China (21306044).

\section{References}

[1] B. Torrestiana-Sanchez, R. I. Qrtiz-Basurto, E. B.-D. L. Fuente, Effect of nonsolvents on properties of spinning solutions and polyethersulfone hollow fiber ultrafiltration membranes, $\mathrm{J}$. Membr. Sci. 152 (1999) 19-28.

[2] B. K. Chaturvedi, A. K. Ghosh, V. Ramachandhran, M. K. Trivedi, M. S. Hanra, B. M. Misra, Preparation, characterization and performance of polyethersulfone ultrafiltration membranes, Desalination 133 (2001) 31-40.

[3] Y. J. Jo, E. Y. Choi, S. W. Kim, C. K. Kim, Fabrication and characterization of a novel polyethersulfone/aminated polyethersulfone ultrafiltration membrane assembled with zinc oxide 


\section{ACCEPTED MANUSCRIPT}

nanoparticles, Polymer 87 (2016) 290-299.

[4] J. Barzin, B. Sadatnia, Theoretical phase diagram calculation and membrane morphology evaluation for water/solvent/polyethersulfone systems, Polymer 48 (2007) 1620-1631.

[5] S. S. Madaeni, L. Bakhtiari, Thermodynamic-based predictions of membrane morphology in water/dimethylsulfoxide/polyethersulfone systems, Polymer 53 (2012) 4481-4488.

[6] Z. Yi, L.-P. Zhu, L. Cheng, B.-K. Zhu, Y.-Y. Xu, A readily modified polyethersulfone with amino-substituted groups: Its amphiphilic copolymer synthesis and membrane application, Polymer 53 (2012) 350-358.

[7] Z.-L. Xu, F. A. Qusay, Polyethersulfone(PES) hollow fiber ultrafiltration membranes prepared by PES/non-solvent/NMP solution, J. Membr. Sci. 233 (2004) 101-111.

[8] J.-Y. Huang, J.-M. Xue, K.-W. Xiang, X. Zhang, C. Cheng, S.-D. Sun, C.-S. Zhao, Surface modification of polyethersulfone membranes by blending triblock copolymers of methoxyl poly(ethylene glycol)-polyurethane-methoxyl poly(ethylene glycol), Colloids Surf., B: Biointerfaces 88 (2011) 315-324.

[9] J.-F. Li, Z.-L. Xu, H. Yang, L.-Y. Yu, M. Liu, Effect of $\mathrm{TiO}_{2}$ nanoparticles on the surface morphology and performance of microporous PES membrane, Appl. Surf. Sci. 255 (2009) $4725-4732$.

[10] H. Susanto, M. Ulbrichta, Characteristics, performance and stability of polyethersulfone ultrafiltration membranes prepared by phase separation method using different macromolecular additives, J. Membr. Sci. 327 (2009) 125-135.

[11] Y.-X. Ma, F.-M. Shi, J. Ma, M.-N. Wu, J. Zhang, C.-J. Gao, Effect of PEG additive on the morphology and performance of polysulfone ultrafiltration membranes, Desalination 272 (2011) 


\section{ACCEPTED MANUSCRIPT}

$51-58$.

[12] L.-J. Zhu, L.-P. Zhu, J.-H. Jiang, Z. Yi, Y.-F. Zhao, B.-K. Zhu, Y.-Y. Xu, Hydrophilic and anti-fouling polyethersulfone ultrafiltration membranes with poly(2-hydroxyethylmethacrylate) grafted silica nanoparticles as additive, J. Membr. Sci. 451 (2014) 157-168.

[13] S.-W. Li, Z.-Y. Cui, L. Zhang, B.-Q.o He, J.-X. Li, The effect of sulfonated polysulfone on the compatibility and structure of polyethersulfone-based blend membranes, J. Membr. Sci. 513 (2016) $1-11$.

[14] D. Qadir, H. Mukhtar, L. K. Keong, Synthesis and characterization of polyethersulfone/carbon molecular sieve based mixed matrix membranes for water treatment applications, Procedia Engineering 148 (2016) 588-593.

[15] J. Guo, A. Sotto, A. Martín, J. Kim, Preparation and characterization of polyethersulfone mixed matrix membranes embedded with Ti- or Zr-incorporated SBA-15 materials, J. Ind. Eng. Chem. 45 (2017) 257-265.

[16] P. Juřík, PetrSlepička, Z. Kolská, V. Švorčík, Change of surface properties of gold nano-layers deposited on polyethersulfone film due to annealing, Mater. Lett. 165 (2016) 33-36.

[17] S.-J. Han, L.-L. Mao, T. Wu, H.-Z. Wang, Homogeneous polyethersulfone hybrid membranes prepared with in-suit synthesized magnesium hydroxide nanoparticles by phase inversion method, J. Membr. Sci. 516 (2016) 47-55.

[18] H. Mahdavi, F. Razmi, T. Shahalizade, Polyurethane TFC nanofiltration membranes based on interfacial polymerization of poly(bis-MPA) and MDI on the polyethersulfone support, Sep. Purif. Technol. 162 (2016) 37-44.

[19] Z.-L. Cheng, X. Li, Y.-D. Liu, T.-S. Chung, Robust outer-selective thin-film composite 


\section{ACCEPTED MANUSCRIPT}

polyethersulfone hollow fiber membranes with low reverse salt flux for renewable salinity-gradient energy generation, J. Membr. Sci. 506 (2016) 119-129.

[20] A. J. Castro, Methods for making microporous products, United States Patent US, 1981/4247498.

[21] D. R. Lloyd, K. E. Kinzer, H. S. Tseng, Microporous membrane formation via thermally induced phase separation. I. Solid-liquid phase separation, J. Membr. Sci. 52 (1990) 239-261.

[22] D. R. Lloyd, S. S. Kim, K. E. Kinzer, Microporous membrane formation via thermally-induced phase separation. II. Liquid-liquid phase separation, J. Membr. Sci. 64 (1991) 1-11.

[23] A. A. Alwattari, D. R. Lloyd, Microporous membrane formation via thermally-induced phase separation. VI. Effect of diluent morphology and relative crystallization kinetics on polypropylene membrane structure, J. Membr. Sci. 64 (1991) 55-67.

[24] K. S. McGuire, D. R. Lloyd, G. B. A. Lim, Microporous membrane formation via thermally-induced phase separation. VII: Effect of dilution, cooling rate, and nucleating agent addition on morphology, J. Membr. Sci. 79 (1993) 27-34.

[25] H. Matsuyama, S. Berghmans, D. R. Lloyd, Formation of hydrophilic microporous membranes via thermally induced phase separation, J. Membr. Sci. 142 (1998) 213-224.

[26] M.-C.Yang, J.-S Perng, Comparison of solvent removal methods of microporous polypropylene tubular membranes via thermally induced phase separation using a novel solvent: Camphene, J. Polym. Res. 6 (1999) 251-258.

[27] M. Liu, S.-H. Liu, Z.-L. Xu, Y.-M. Wei, H. Yang, Microporous polymeric membranes via thermally induced phase separation: A review, Front. Chem. Eng. 10 (2016) 57-75.

[28] H. Matsuyama, T. Maki, M. Teramoto, K. Asano, Effect of polypropylene molecular weight on porous membrane formation by thermally induced phase separation, J. Membr. Sci. 204 (2002) 


\section{ACCEPTED MANUSCRIPT}

323-328.

[29] M. J. Park, S. C. Noh, C. K. Kim, Effects of the phase behavior of the diluent mixture on the microstructure of polyethylene membranes formed by thermally induced phase separation process, Ind. Eng. Chem. Res. 52 (2013) 10690-10698.

[30] H.-Q. Liang, Q.-Y. Wu, L.-S. Wan, X.-J. Huang, Z.-K. Xu, Thermally induced phase separation followed by in situ sol-gel process: A novel method for $\mathrm{PVDF} / \mathrm{SiO}_{2}$ hybrid membranes, J. Membr. Sci. 465 (2014) 56-67.

[31] J. Zhou, H. Zhang, H.-T. Wang, Q.-G. Du, Effect of cooling baths on EVOH microporous membrane structures in thermally induced phase separation, J. Membr. Sci. 343 (2009) 104-109.

[32] J. Zhang, S.-J. Chen, J. Jin, X.-M. Shi, X.-L. Wang, Z.-Z. Xu, Non-isothermal melt crystallization kinetics for ethylene-acrylic acid copolymer in diluents via thermally induced phase separation, J. Therm. Anal. Calorim. 101 (2010) 243-254.

[33] X.-T. Han, H.-Y. Ding, L.-H. Wang, C.-F. Xiao, Effects of nucleating agents on the porous structure of polyphenylene sulfide via thermally induced phase separation, J. Appl. Polym. Sci. 107 (2008) 2475-2479.

[34] R. H. Mehta, D. S. Kalika, Characteristics of poly(ether ether ketone) microporous membranes prepared via thermally induced phase separation (TIPS), J. Appl. Polym. Sci. 66 (1997) $2347-2355$.

[35] H. Matsuyama, M. Kakemizu, T. Maki, M. Tearamoto, K. Mishima, K. Matsuyama, Preparation of porous poly(oxymethylene) membrane with high durability against solvents by a thermally induced phase-separation method, J. Appl. Polym. Sci. 83 (2002) 1993-1999.

[36] I. J. Roh, S. Ramaswamy, W. B. Krantz, A. R. Greenberg, Poly(ethylene chlorotrifluoroethylene) 


\section{ACCEPTED MANUSCRIPT}

membrane formation via thermally induced phase separation (TIPS), J. Membr. Sci. 362 (2010) 211-220.

[37] H.-J. Tao, J. Zhang, X.-L. Wang, Effect of diluents on the crystallization behavior of poly(4-methyl-1-pentene) and membrane morphology via thermally induced phase separation, $\mathrm{J}$. Appl. Polym. Sci. 108 (2008) 1348-1355.

[38] G. Conoscenti, T. Schneider, K. Stoelzel, F. C. Pavia, V. Brucato, C. Goegele, V. L. Carrubba, G. Schulze-Tanzil, PLLA scaffolds produced by thermally induced phase separation (TIPS) allow human chondrocyte growth and extracellular matrix formation dependent on pore size, Mater. Sci. Eng., C 80 (2017) 449-459.

[39] T. Kitaura, W. N. Fadzlina, Y. Ohmukai, T. Maruyama, H. Matsuyama, Preparation and characterization of several types of polyvinyl butyral hollow fiber membranes by TIPS, J. Appl. Polym. Sci. 127 (2013) 4072-4078.

[40] F. J. Tsai, J. M. Torkelson, Roles of phase separation mechanism and coarsening in the formation of poly (methyl methacrylate) asymmetric membranes, Macromolecules 23 (1990) 775-784.

[41] C.-Y. Gao, A. Li, L.-X. Feng, X.-S. Yi, J.-C. Shen, Factors controlling surface morphology of porous polystyrene membranes prepared by thermally induced phase separation, Polym. Int. 49 (2000) 323-328.

[42] Y. Mino,T. Ishigami,Y. Kagawa, H. Matsuyama, Three-dimensional phase-field simulations of membrane porous structure formation by thermally induced phase separation in polymer solutions, J. Membr. Sci. 483 (2015) 104-111.

[43] Y.-D. He, Y.-H. Tang, X.-L. Wang, Dissipative particle dynamics simulation on the membrane formation of polymer-diluent system via thermally induced phase separation, J. Membr. Sci. 368 


\section{ACCEPTED MANUSCRIPT}

(2011) 78-85.

[44] H. Matsuyama, Y. Takida, T. Maki, M. Teramoto, Preparation of porous membrane by combined use of thermally induced phase separation and immersion precipitation, Polymer 43 (2002) $5243-5248$.

[45] X.-F. Li, Y.-G. Wang, X.-L. Lu, C.-F. Xiao, Morphology changes of polyvinylidene fluoride membrane under different phase separation mechanisms, J. Membr. Sci. 320 (2008) 477-482.

[46] B.-J. Cha, J.-M. Yang, Preparation of poly (vinylidene fluoride) hollow fiber membranes for microfiltration using modified TIPS process, J. Membr. Sci. 29 (2007) 191-198.

[47] Z.-X. Zhu, G.-Z. Meng, c-TIPS method for membrane production, Membrane Science and technology (China) 30 (2010) 1-6.

[48] Z.-P. Lu, X.-L. Lü, C.-R. Wu, Y. Jia, X. Wang, H.-Y. Chen, Q.-J. Gao, Preparation of polyvinylidene fluoride hollow fiber porous membrane via a low thermally induced phase separation, Membrane Science and technology (China) 32 (2012) 12-7, 22.

[49] M. Liu, Y.-M. Wei, Z.-L. Xu, R.-Q. Guo, L.-B. Zhao, Preparation and characterization of polyethersulfone microporous membrane via thermally induced phase separation with low critical solution temperature system, J. Membr. Sci. 437 (2013) 169-178.

[50] S.-H. Liu, Z.-L. Xu, M. Liu, Y.-M. Wei, F. Guo, Preparation and characterization of PES/CA microporous membranes via reverse thermally induced phase separation process, Polym. Eng. Sci. (2017) DOI 10.1002/pen.24545.

[51] S.-H. Liu, M. Liu, Z.-L. Xu, Y.-M. Wei, A novel PES-TiO ${ }_{2}$ hollow fiber hybrid membrane prepared via sol-gel process assisted reverse thermally induced phase separation (RTIPS) method, J. Membr. Sci. 528 (2017) 303-315. 


\section{ACCEPTED MANUSCRIPT}

[52] L.-B. Zhao, M. Liu, Z.-L. Xu, Y.-M. Wei, M.-X. Xu, PSF hollow fiber membrane fabricated from PSF-HBPE-PEG400-DMAc dope solutions via reverse thermally induced phase separation, Chem. Eng. Sci. 137 (2015) 131-139.

[53] Charles M. Hansen, Hansen Solubility Parameters: A User's Handbook (2nd Edition). CRC Press, New York, USA, 2007.

[54] D. W. Van Krevelen, Properties of polymers (4th Edition). Elsevier, New York, USA, 2009.

[55] Y.-J. Wang, D. Kim, Crystallinity, morphology, mechanical properties and conductivity study of in situ formed $\mathrm{PVdF} / \mathrm{LiClO}_{4} / \mathrm{TiO}_{2}$ nanocomposite polymer electrolytes, Electrochim. Acta 52 (2007) 3181-3189.

[56] C.-S. Feng, B.-L. Shi, G.-M. Li, Y.-L. Wu, Preparation and properties of microporous membrane from poly(vinylidene fluoride-co-tetrafluoroethy-lene) (F2.4) for membrane distillation, J. Membr. Sci. 237 (2004) 15-24.

\section{Highlights}

$>$ A group contribution estimate of phase separation temperature for RTIPS was proposed.

$>\quad$ Phase separation temperatures were linearly dependent on Hansen solubility parameters.

$>$ PES membranes with bi-continuous structure were acquired from RTIPS process.

$>$ PES membranes prepared by RTIPS showed good permeation and mechanical properties. 